Portland State University

PDXScholar

6-29-1994

\title{
Hermann Hesses Unterm Rad: Identitätssuche eines Jugendlichen
}

Martina Mangan

Portland State University

Follow this and additional works at: https://pdxscholar.library.pdx.edu/open_access_etds

Part of the German Language and Literature Commons Let us know how access to this document benefits you.

Recommended Citation

Mangan, Martina, "Hermann Hesses Unterm Rad: Identitätssuche eines Jugendlichen" (1994).

Dissertations and Theses. Paper 4847.

https://doi.org/10.15760/etd.6723

This Thesis is brought to you for free and open access. It has been accepted for inclusion in Dissertations and Theses by an authorized administrator of PDXScholar. Please contact us if we can make this document more accessible: pdxscholar@pdx.edu. 


\section{THESIS APPROVAL}

The abstract and thesis of Martina Mangan for the Master of Arts degree in German were presented June 29th, 1994 and accepted by the thesis committee and the department.

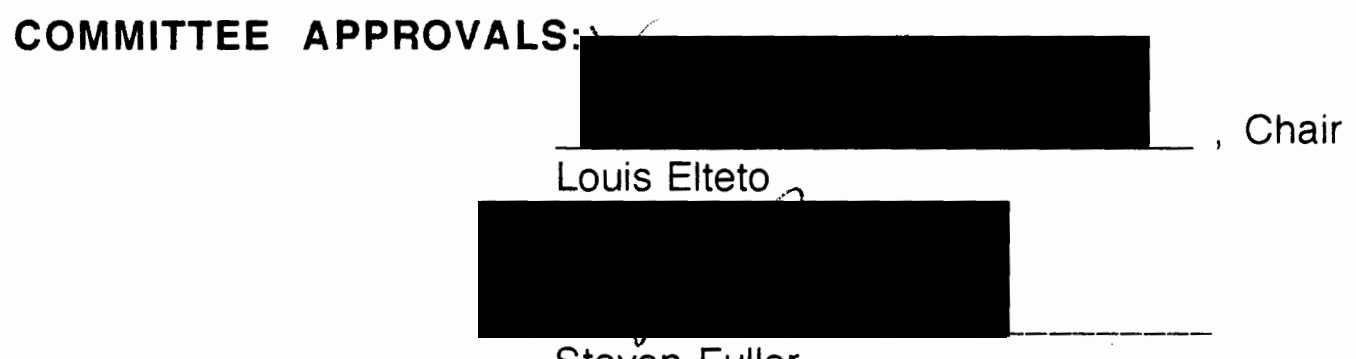

Steven Fuller

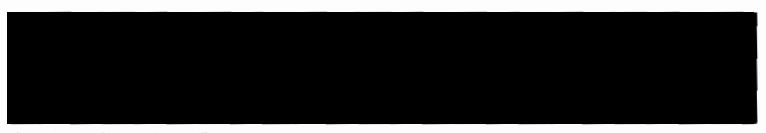

Friedrich Schuler

Representative of the Office of Graduate Studies

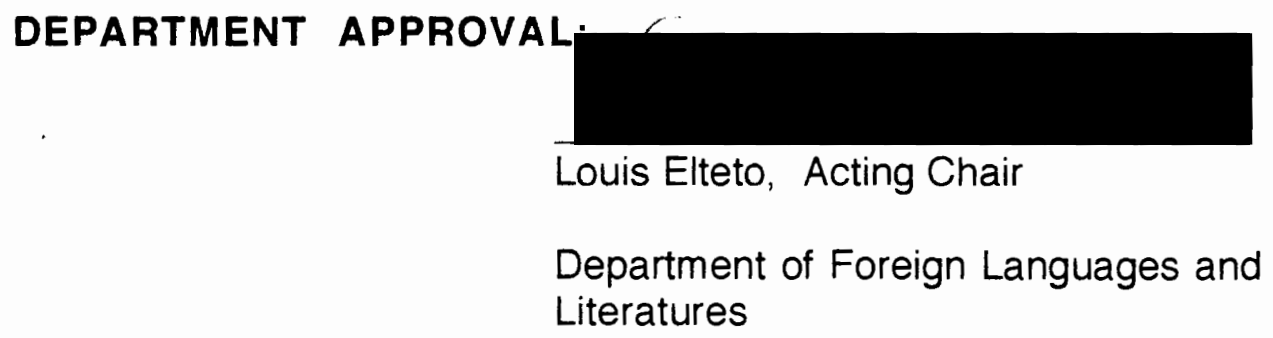

ACCEPTED FOR PORTTLAND STATE UNIVERSITY BY THE LIBRARY

by

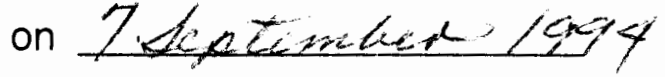




\section{ABSTRACT}

An abstract of the thesis of Martina Mangan for the Master of Arts in German presented June 29th, 1994.

Title: Hermann Hesses Unterm Rad : Identitätssuche eines Jugendlichen

Hermann Hesse's reflection on youth is one of his most popular themes. In his novel Unterm Rad (1906), Hesse explores youth and their search for identity. The author not only accuses the German educational system of at the turn of the century, but also the teachers and parents, of standing in the children's way in developing an individualized personality. According to Hesse, this development, however painful, is the primary responsibility of the adolescent.

Hermann Hesse feels strongly about becoming a personality, namely the priviledge to feel, act, and think independently of the masses. Every individual has an obligation to follow his inner voice and to develop his own identity.

The first part of this thesis concentrates on the novel Unterm Rad and consists of a summary, thematic discussion, the novel's presentation and its

original and succeeding receptions. It then discusses the definition and theory of "identity" in regard to young people. By focusing on the two protagonists Giebenrath and Heilner, their goals and the reality of their lives, their struggle on their way to adulthood becomes apparent.

Finally this thesis exlores Hesse's own childhood and youth and examines the autobiographical elements in the literary figures of this novel. 
HERMANN HESSES UNTERM RAD:

IDENTITÄTSSUCHE EINES JUGENDLICHEN

by

MARTINA MANGAN

A thesis presented to the Department of Foreign Languages and Literatures and the Graduate School in partial fulfillment of the requirements for the degree of

MASTER OF ARTS

in

GERMAN

PORTLAND STATE UNIVERSITY

1994 


\section{DANKSAGUNG}

Ich möchte mich bei Herrn Dr. Louis Elteto herzlich bedanken, unter dessen Leitung diese Arbeit entstanden ist. Seine Unterstützung und Hilfbereitschaft werden sehr geschätzt.

Weiterhin gilt mein Dank meinen Eltern, Christel und Wolfgang Schiemann, für inre liebevolle, lebenslange Unterstützung. Ohne ihre Ermutigungen wäre dieses zweite Studium nicht zu verwirklichen gewesen. Schließlich möchte ich mich bei meinem Mann John, meinen Kindern Christopher und Natascha und allen Freunden bedanken, die im Laufe des langen Studiums Verständnis und Geduld gezeigt haben.

Martina Mangan

Salem, im Juni 1994 


\section{INHALTSVERZEICHNIS}

Genehmigung ...............................................................

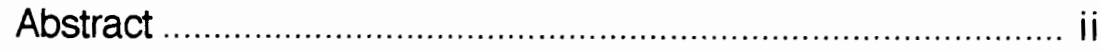

Titelblatt ................................................................... ii

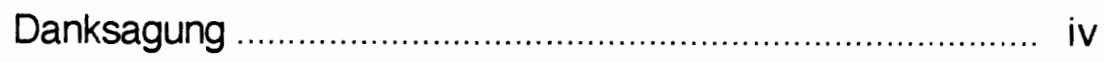

Inhaltsverzeichnis .....................................................

\section{KAPITEL}

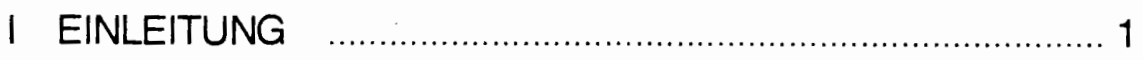

॥ DAS WERK UNTERM RAD

1. Der Inhalt ............................................................ 10

2. Thematische Einordnung ..................................... 16

3. Aufbau und Darstellung ......................................... 19

4. Zeitgenössische und aktuelle Wirkung ....................... 22

III IDENTITÄTSSUCHE EINES JUGENDLICHEN

1. Identität: Definition und Theorie ................................26

2. Wünsche, Ziele und Realität im Leben des Hans Giebenrath ............................................... 30

3. Die Figur des Hermann Heilner ................................ 42

IV "DICHTUNG UND WAHRHEIT"

1. Biographischer Abriß .......................................... 45

2. Autobiographische Elemente in den literarischen Figuren ............................................................. 53

V ZUSAMMENFASSUNG ...................................... 58

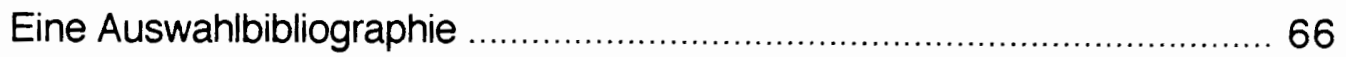




\section{KAPITEL I}

\section{EINLEITUNG}

Das Schicksal des begabten Hans Giebenrath, den der Ehrgeiz seines Vaters und der Lokalpatriotismus seiner Heimatstadt „unters Rad" drängen, steht für eine Erziehung, die ohne Rücksicht auf die innere Reifung und Entwicklung heranwachsenden Menschen das Individuum in ein System der Zwänge einspannt, in dem es letztlich zerbrechen muß.

In dieser Arbeit soll dargestellt werden, wie Hermann Hesse in seinem Roman Unterm Rad seine eigenen Jugendkrisen stilisiert, indem er seine persönlichen Konflikte auf zwei Figuren - Giebenrath und Heilner - überträgt. Hesse selbst wurde, da er sich nicht anpassen konnte und im damaligen Schulsystem schließlich scheiterte, von den Institutionen und seinen Eltern zum Außenseiter gestempelt. Der von Hesse erlebte und künstlerisch gestaltete Prozeß der Identitätssuche läßt sich entwicklungspsychologisch und psychoanalytisch als Pubertätskrise, als Problem der lch-Findung und der Entwicklung eines Ich-Ideals deuten. Schon Hesses frühe Briefe zeigen, daß er als Jugendlicher Energie zur Opposition besaß und in der schriftstellerischen Tätigkeit einen Ausgleich fand, der inm das physische und psychische Überleben ermöglichte. Hans Giebenrath bleibt ein solcher Ausgleich versagt. Im Zusammenhang mit der nicht geglückten Identitätsfindung läßt sich darauf verweisen, daß Giebenrath die mit dem Leistungsdruck verbundene Triebverdrängung (Spieltrieb, Sexualtrieb) nicht sublimieren kann. Eine 
Rettung durch kreatives Verarbeiten, im Gegensatz zu dem dichtenden Hermann Heilner und Hermann Hesse selbst, wird Hans nicht ermöglicht. Da die Suche nach der eigenen Identität sowohl bei den Jugendlichen Hans Giebenrath und Hermann Heilner, als auch dem jungen Hermann Hesse zu einer Krise führt, bietet sich ein direkter Vergleich zwischen den Protagonisten des Romans und der Kindheit und Jugend des Autors an.

Um Hesses und Giebenraths Scheitern am Schulsystem des beginnenden 20. Jahrhunderts besser zu verstehen, werden im folgenden die Schulverhältnisse um 1900 erläutert; ferner wird die Klosterschule in Maulbronn, an der schon Friedrich Hölderlin und Georg Herwegh inre schulische Ausbildung genossen, vorgestellt.

Bis zum Jahre 1920 waren in den meisten Ländern die höheren und niederen Schuleinrichtungen völlig voneinander getrennt. Zu den höheren Schulen gehörten meist besondere Vorschulen, welche die Schüler auf den Besuch der höheren Schule vorbereiteten. Ungefähr die Hälfte aller Schüler höherer Lehranstalten erhielt dort ihren ersten Unterricht. Außerdem bestand die Möglichkeit, die Kinder in privaten Volksschulen oder durch Privatlehrer auf den Besuch der höheren Schule vorbereiten zu lassen. Diese privaten Schulen erhoben ein so hohes Schulgeld, daß es nur den Kindern der Reichen möglich war, sie zu besuchen. In Preußen kamen vor dem ersten Weltkrieg nur fünf Prozent aller Schüler in den Genuß einer weitertührenden Schulbildung. 1

Lediglich wenigen begabten Kindern aus ärmeren Schichten wurde der Zugang über Eingangsexamen, wie z.B. das Stuttgarter "Landexamen" , zur höheren Bildung über Lehrerseminare, Kadettenanstalten oder Klosterschulen ermöglicht. Die Volksschule wurde als Armeleuteschule bezeichnet. Im Jahre

1Karl-Heinz Günther u.a., Geschichte der Erziehung (Berlin: Volk und Wissen Volkseigener Verlag, 1957) 354. 
1899 betrugen im Deutschen Reich die Kosten für einen Volksschüler 40 Mark, für einen Schüler der höheren Lehranstalten aber 243 Mark. 2

Zu Ende des 19. und Anfang des 20. Jahrhunderts stand dem wenig ausgebauten Volksschulwesen ein differenziertes höheres Schulwesen gegenüber. Die Gymnasien gehörten zu den ältesten Typen der höheren Schulen. In ihren Lehrplänen nahm der Unterricht in den alten Sprachen (Latein, Griechisch, Hebräisch) den größten Raum ein.

Schon 1885 wurde Kritik an den humanistischen Bildungsanstalten geübt, die von den Kindern verlangten, sich „acht bis zehn Jahre lang wöchentlich 20 , ja 30, 40 Stunden mit solchem geisttötenden Formalismus abzuquälen, wie es der klassische Sprachunterricht in seiner gegenwärtigen Gestalt ist". 3

So wurden die Kinder in den höheren Schulen nicht nur mit endlosen schriftlichen Übersetzungen, dem Auswendiglernen von langen Reihen von Vokabeln und grammatischen Regeln gequält, sondern durch die klassische Erziehung auch nicht selten zum sozialen Außenseiter gemacht. Dies wird von Christensen deutlich gemacht, indem er schreibt:

Nun aber bilden ihre alten Schmöker ein treffliches Mittel, um zwischen den sogenannten 'klassisch Gebildeten' und den anderen Menschenkindern einen recht dicken Strich ziehen zu können, und das verschafft innen Ansehen. Es ist ja in der Tat auch sehr angenehm, wenn man sich auf eine so bequeme Art und Weise das Recht erwerben kann, auf neunzehn Zwanzigstel der Menschheit mit einem mitleidigen Lächeln herabblicken zu dürfen. 4

2Günther 355.

3Jens Christensen, Der moderne Bildungsschwindel in Schule und Familie sowie im täglichen Verkehr (Leipzig: ohne Verlagsangabe, 1885) 64.

4 Christensen 64. 
Doch nicht nur Eltern und Schriftsteller, die eine abgerundetere Ausbildung für die Jugend wünschten, übten Kritik am damaligen Schulsystem. Wenn auch unter völlig unterschiedlichen politischen Motiven, so sahen auch die Führenden des Landes eine Notwendigkeit für Bildungsreform. Bei einer Konferenz in Berlin im Dezember 1890 hielt Kaiser Wilhelm II eine Rede, in der er auf Bildungsreform drängte, schließlich galt es in den deutschen Gymnasien Deutsche zu erziehen, nicht Römer und Griechen. 5

In Maulbronn war seit den Tagen der Reformation in der ehemaligen Zisterzienserabtei, gegründet im Jahre 1147, eine protestantische Klosterschule untergebracht. Sie war eines der "niederen" evangelischen Seminare des Landes Württemberg, in dem die vierzehn- bis achtzehnjährigen Knaben aufs Studium der Theologie vorbereitet wurden. 6 Hier bestimmten seit dem 16. Jahrhundert die Prinzipien evangelischer Jugenderziehung den Lehrbetrieb. Griechisch und Latein wurden zwar besonders gepflegt, aber diese klassischen Studien strebten keine weltliche Bildung an, sondern standen im Dienste lutherischer Rechtgläubigkeit. Wie schon zu Zeiten Melanchthons blieb die Frömmigkeit Hauptbestandteil des gemischten Lehrprogramms aus altsprachlichen Übersetzungsübungen, deutschsprachigem Literaturwissen und protestantischer Bibelgelehrsamkeit.7

Das konnte für künftige Pastoren und Religionslehrer ein angemessener Lehrplan sein, doch für eine hellhörige, von der Entwicklung des industriellen Kapitalismus des späten 19. Jahrhunderts berührte Jugend war er überholt. Auf sie wirkten diese Lehrinhalte einengend und isolierend.

5 Mark Boulby, Hermann Hesse: His Mind and Art (Ithaca: Cornell University Press, 1967) 40.

6Fritz Böttger, Hermann Hesse: Leben, Werk, Zeit (Berlin: Verlag der Nation, 1974) 37.

7 Böttger 38. 
Was den Geist der Zeit betraf, so hatte sich die Anstalt vor allem dem deutschen Militarismus angepasst. In der Turnstunde zum Beispiel tobte ein wilhelminischer Schultyrann. Hesse beschreibt in einem Brief aus Maulbronn vom 11. Oktober 1891 wie der Turnlehrer die Schüler ansprach: „Sie sollten zum Militär kommen! Sie sollte man auf Staatskosten schlauchen für Ihr ewiges Phlegma!" 8

Das Kloster Maulbronn beherbergt heute ein evangelisch-theologisches Seminar.

Als Hermann Hesse 1962 mit 85 Jahren starb, hinterließ er ein Gesamtwerk von fast 40 Büchern: Romane, Erzählungen, Gedichte, Betrachtungen, die (einer Schätzung von 1987 zufolge), in über 70 Millionen Exemplaren rund um den Globus verbreitet sind. Nur etwa ein Fünftel dieser Gesamtauflage entfällt auf deutsche Ausgaben. Hesses Resonanz im Ausland (16 Millionen seiner Bücher in den USA, in Japan 15 Millionen, in Lateinamerika 6 Millionen) hat inzwischen auch wieder auf sein eigenes Sprachgebiet zurückgewirkt.9

Weiterhin soll Hermann Hesse im Laufe seines Lebens schätzungsweise 35000 Briefe und Antwortschreiben verfaßt haben, von denen etwa 15000 aufgefunden und ca. 5000 veröffentlicht wurden. Internationale Anerkennung hat Hesse mittlerweile auch als Maler durch Ausstellungen in Europa, Ostasien und Amerika gefunden. Er zeichnete sich außerdem durch seine Arbeit als Herausgeber, Übersetzer, Literaturkritiker, Musikkenner, Humorist und universal gebildeter Humanist aus. Sein Werk ist mehr als nur Literatur, es ist

8Böttger 37 zitiert Ninon Hesse (Hrsg.), Kindheit und Jugend vor Neunzehnhundert. Hermann Hesse in Briefen und Lebenszeugnissen $1877-$ 1895 (Frankfurt a.M.: Suhrkamp Verlag, 1973) 120.

9 Christian Immo Schneider, Hermann Hesse (München: C.H. Beck Verlag, 1991) 7. 
auch Lebenshilfe für Millionen von Lesern und Leserinnen geworden.10 Der einst als "Heiliger der Hippies" bezeichnete Autor - erinnert sei in diesem Zusammenhang nur an die Hesse-Renaissance in Amerika in den 60er und anfangs der 70er Jahre als Reaktion auf den Vietnamkrieg - ist derzeitig zu einer geistigen Potenz mit weltweitem Echo geworden.

Wenn auch Hermann Hesse in der Literaturwisenschaft nicht als Jugendschriftsteller bezeichnet wird, so kann man inn dennoch einen Dichter für die junge Generation nennen. Wie schon die Titel vieler seiner Erzählungen und Romane erkennen lassen, beschäftigt sich Hesse in fast der Hälfte seiner Werke mit dem Thema der Kindheit und Jugend. Einige Beispiele hierfür sind: Aus Kinderzeiten, Der Lateinschüler, Schön ist die Jugend, Demian, Freunde, Der vierte Lebenslauf, Berthold, Kinderseele, Unterbrochene Schulstunde, und viele andere. Immer wieder kehrt Hesse während seiner 60 Jahre währenden Schaffenszeit als Schriftsteller zu den eigenen Erfahrungen aus der Schulzeit zurück. Wie in vielen Werken Hesses findet man auch in Unterm Rad deutliche autobiographische Züge.

Ein weiterer Grund, warum Hermann Hesse als Dichter für jugendliche Leser angesehen werden kann, ist, daß er die Jugend nicht nur darstellt, sondern ihr auch mit vielen seiner Hauptfiguren ein Angebot macht, sich mit innen zu identifizieren. Diese Figuren „verkörpern Stationen eigener Entwicklung, sind abgelegte Häute seines Ichs, sind Protokolle der Stationen fortschreitender Individualisierung und Emanziation".11 Die begeisterte Hesse-Leserin Karin Struck schreibt über ihre eigenen Leseerfahrungen:

Die Personen der Romane und Erzählungen machen ungeheure

10 Schneider 8.

11 Volker Michels (Hrsg.), Über Hermann Hesse Bd. 2 (Frankfurt a. M.: Suhrkamp Verlag, 1977) 136. 
Metamorphosen, Wandlungen, Veränderungen durch. Sie kämpfen um ihre Individuation. Ich nehme an ihren Kämpfen und Wandlungen teil, und es kommt vor, daß ich mich selber in innen erkenne.12

Es ist anzunehmen, daß es vielen Jugendlichen so wie Karin Struck geht, wenn sie Werke von Hesse lesen, denn er schreibt viel über die Liebe, über erste Liebesversuche und über deren Scheitern. Wie die Personen in seinen Romanen und Erzählungen, so sind auch die jungen Leser Suchende. Sie suchen nach dem Sinn des Lebens, der eigenen, noch zu entwickelnden Individualität. Sie sind auch Suchende der Liebe, Suchende im bezug auf inren Platz in der Gesellschaft, Suchende moralischer Werte, wie Giebenrath und Heilner in Unterm Rad und Hermann Hesse selbst.

Indem sich der jugendliche Leser in den literarischen Gestalten Hesses wiedererkennt, werden in deren Auseinandersetzungen die eigenen Probleme angesprochen, ja möglicherweise sogar Lösungsangebote gemacht. Die Probleme vieler seiner Protagonisten haben sinnbildhafte Bedeutung: „Pubertät, also die Notwendigkeit und Bereitschaft zur Wandlung, Veränderung, Differenzierung und Flexibilität, war für inn nichts Einmaliges, altersmäßig und biologisch Fixiertes, sondern geradezu eine Lebensnotwendigkeit." 13

Hesses gesamte Biographie und folglich auch seine schriftstellerische Entwicklung und Wirkung steht unter diesem Vorzeichen. Dieser Author führt seine Leser durch die Darstellung authentischer Krisen nicht nur seine eigene Problematik vor Augen und läßt sie dann im Stich, sondern er führt sie auch durch die Krise hindurch und zeigt innen ihren Sinn.

12Karin Struck in Volker Michels, Über Hermann Hesse 324.

13Michels, Über Hermann Hesse 137. 
Die Entstehung des Werkes Unterm Rad gehört der Gaienhofer Schaffensperiode (1904 - 1912) des Autors an. Peter Camenzind, der 1903 als Vorabdurck in der Neuen Rundschau und 1904 als Buch erscheint, macht den Namen des bis dahin noch unbekannten Autors schlagartig berühmt und eröffnet inm mit dem Signum des gewichtigen Fischer Verlags den Eintritt in die große Literatur. Der Erfolg des Peter Camenzind ermöglicht es inm, das Leben eines freischaffenden Schriftstellers zu führen. Während Hesse zu Hause in Calw bei Vater und Schwestern sitzt und Unterm Rad schrieb, findet seine Frau Maria im badischen Dorf Gaienhofen am Bodensee ein Haus zu mieten. Es ist das erste Haus, die erste Zufluchtsstätte für seine junge Ehe, die erste wirkliche Werkstatt seines Berufes. Hier hat Hesse zum ersten Mal das Gefühl der Seßhaftigkeit.14 Hier in Gaienhofen vollendet Hesse sein zweites größeres Werk.

Unterm Rad erscheint ursprünglich ohne Gattungsbezeichnung. Ein Vorabdruck erfolgt in der Neuen Züricher Zeitung zwischen dem 5. April und 17. Mai 1904. Die erste Niederschrift legt Hesse im April 1904 Samuel Fischer vor, zieht sie aber noch einmal zur Überarbeitung zurück. Am 25. November 1904 schreibt Hesse an seinen Halbbruder Karl Isenberg über sein neuestes Werk folgendes:

Unterm Rad wird nächstes Jahr als Buch erscheinen, in Kleinigkeiten gemildert. Hoffentlich nimmst Du an den paar salzigen Stellen nicht zu sehr Anstoß. Die Schule ist die einzige moderne Kulturfrage, die ich ernst nehme und die mich gelegentlich aufregt. An mir hat die Schule viel kaputtgemacht, und ich kenne wenig bedeutendere Persönlich-

14Bernhard Zeller, Hermann Hesse mit Selbstzeugnissen und Bilddokumenten 29. Auflage (Reinbek b. Hamburg: Rowohlt Taschenbuch Verlag, 1993) 51. 
keiten, denen es nicht ähnlich ging. Gelernt habe ich dort nur Latein und Lügen, denn ungelogen kam man in Calw und im Gymnasium nicht durch - wie unser Hans beweist, den sie ja in Calw, weil er ehrlich war, fast umbrachten. Der ist auch, seit sie inm in der Schule das Rückgrat gebrochen haben, immer unterm Rad geblieben.15

1905 erscheint das Werk (vordatiert auf 1906) als Buch im S. Fischer Verlag und erreicht im Jahr 1918 bereits eine Auflage von 100 Tausend. Von 1933 bis Kriegsende ist das Buch vergriffen und darf nicht nachgedruckt werden. Erste Neuauflage, vom Autor geringfügig bearbeitet, erscheint im Jahr 1951.

15Siegfried Unseld, Hermann Hesse: Werk und Wirkungsgeschichte (Frankfurt a. M.: Suhrkamp Verlag, 1985) 24. Zitiert aus Hermann Hesses Gesammelten Briefen, Bd I, 130. 
KAPITEL \|

\section{DAS WERK UNTERM RAD}

\section{Der Inhalt}

Hans Giebenrath steht im Mittelpunkt der Erzählung. Er ist der einzige Sohn des Agenten Joseph Giebenrath und dessen kränklicher, früh verstorbener Frau. Hans ist ein begabter, wenn auch körperlich eher schwächlicher Junge, der in einer Kleinstadt im Schwarzwald die Lateinschule besucht. Die Lehrer, der Rektor, der Stadtpfarrer, ja sogar seine Mitschüler geben zu, Hans sei etwas Besonderes. Er soll deshalb am württembergischen "Landexamen" in Stuttgart teilnehmen, mit dessen Bestehen ein Studienplatz am protestantischen Seminar in Maulbronn und später im Tübinger Stift verbunden war.

Der ehrgeizige Vater, der inn nach den täglichen Schulstunden noch Privatunterricht nehmen läßt, sieht in seinem Sohn den einzigen Weg zum sozialen Aufstieg. Mit Aussicht auf ein Pfarr- oder Lehramt wird der Junge selbst vom Ehrgeiz gepackt. Hans sitzt bis spät in die Nacht über seinen Büchern. Es bleibt wenig Zeit zum Spielen, das Angeln war inm jetzt verboten und der Kontakt zu seinen Schulkameraden geht allmählich verloren. Als kurz vor dem Landexamen die Kopfschmerzen zunehmen und die Vergeistigung des Jungen eklatant wird, empfiehlt der Vater Spaziergänge, bei denen man ja auch ein Buch mitnehmen könne.

Auf der Reise nach Stuttgart ist der Vater nervös, der Sohn wird immer stiller und ängstlicher. Die Lateinprüfung am ersten Tag kommt inm leicht vor: er schöpft etwas Mut. Nach der Prüfung in Griechisch und dem deutschen Aufsatz 
hat er ein schlechtes Gefühl. Er fühlt sich elend und beantwortet die unaufhörlichen Fragen seines Vater nur knapp. Schließlich übersteht Hans die mündlichen Prüfungen am letzten Tag und will danach sofort abreisen. Einige Tage später erfährt Hans, daß er das Examen als Zweiter bestanden hatte. Der Rektor gibt inm nun, acht Tage vor Beginn der Sommerferien, frei. Hans erfüllt ein heißes Gefühl der Dankbarkeit. Nun konnte er studieren! Der Vater ist außer sich vor Stolz und gibt Hans Geld, damit er sich ein Messer zum Schneiden einer Angelrute kaufen könne.

Sieben Wochen Sommerferien stehen Hans bevor. Endlich wieder angeln, baden, die Natur genießen. Er möchte noch einmal unbeschwert die Ferien, wie während seiner Kindheit, genießen können. Doch schon am Morgen des zweiten Ferientags, als er dem Stadtpfarrer Fische bringt, die er geangelt hatte, schlägt dieser vor fürs Seminar vorzuarbeiten, um auch dort möglichst der Beste zu sein. Noch am gleichen Nachmittag sitzt Hans beim Pfarrer in der Studierstube und lernt Griechisch.

Einige Tage später erscheint der Rektor in Hause Giebenrath. Er möchte Hans nichts aufzwingen, wozu er keine Lust habe, schlägt jedoch vor, mit inm Homer zu lesen und beim Professor Privatstunden in Mathematik zu nehmen. Hans sagt freudig zu und verspricht sein Bestes zu tun. In der folgenden Zeit bekommt er schon ein schlechtes Gewissen, wenn er mal eine Stunde angelt oder spazierengeht. Bald häuft sich die Arbeit bis spät am Abend. Sein Kopfweh wird wieder häufiger. Schließlich gibt er das Angeln - außer dem Lernen seine einzige Leidenschaft - ganz auf, da er mangels Aufmerksamkeit sowieso fast keine Fische mehr fängt.

Hans kommt zum Seminar ins ehemalige Zisterzienserkloster Maulbronn, welches wunderschön gelegen, weitab von den zerstreuenden Einflüssen der 
Städte, ja sogar des Familienlebens entzogen ist. Er bekommt seinen Platz im Schafsaal Hellas mit neun anderen Knaben zugewiesen. Es ist inm eigentümlich ums Herz als der Vater Abschied nimmt. Am ersten Abend kann er lange nicht einschlafen. Nach und nach lernt er seine neuen Kameraden kennen, doch ist er zu schüchtern, als ihm ein Junge stürmisch seine Freundschaft anbietet. Hans lehnt ab und bleibt allein. Er studiert fleißig, sieht aber mit Neid und Sehnsucht, wie sich Freundschaften entwickeln. Er wartet darauf, daß inn einer hole, mitreiße und zum Glücklichsein zwinge.

Hermann Heilner, ein junger Dichter und eine weniger komplizierte Erscheinung, verspottet Hans zunächst als einen Streber. Auch er sucht vergebens nach einem Freund und streift täglich während der Ausgangsstunde durch die Wälder. Spät im Oktober treffen sich Hans und Hermann zufällig während eines Spaziergangs, unterhalten sich, erfahren über des Anderen Wünsche und Sorgen. Noch am gleichen Abend gibt es im Schlafsaal eine Rauferei zwischen Hermann und einem Stubengenossen. Hans sieht ängstlich $z u$, bewundert Heilner jedoch, wie er später ohne Hemmungen vor den anderen weint. Hermann zieht sich auf den Flur zurück, Hans folgt inm. Als Hans seinen Kameraden anspricht, wird er zunächst abgewiesen, doch dann zurückgehalten. Hermann zieht Hans an sich und küßt inn. Es bahnt sich eine Freundschaft an, die abenteuerliche, ja vielleicht sogar gefährliche Züge trägt. Die Beiden gelten als das ungleichste Paar: der Leichtsinnige und der Gewissenhafte.

Die Abendstunden, die Hans bisher zum Büffeln benützt hatte, werden in der Folgezeit immer mehr von der Freundschaft mit Hermann in Anspruch genommen. Für Hans eröffnen sich Bereiche, die den Sinn des zielstrebigen Lernens in Frage stellen. Deswegen sinken seine schulischen Leistungen bald 
ab. Für den manchmal schwermütigen Dichter wird Hans zum gefügigen Freund und Tröster. Obwohl inm die Schule immer größere Sorgen bereitet, ist Hans doch stolz in seinem Bewußtsein für den Freund unentbehrlich zu ein.

Nach einem Streit zwischen dem Knaben Lucius und Hermann bekommt der Letztere eine schwere Karzerstrafe auferlegt. Hans hat jetzt nicht den Mut zu seinem Freund zu stehen. Hermann nennt Hans einen Feigling. Am 24. Dezember trennen sich die beiden Freunde ohne Gruß und reisen heim in die Weihnachtsferien.

Im Januar, acht Tage nach dem Begräbnis eines Kameraden, der ins Eis eingebrochen und in einem See ertrunken war, liegt Heilner allein im Krankenzimmer. Hans besucht inn und bittet Hermann noch einmal sein Freund zu sein. Er bittet um Verzeihung und will lieber Letzter in der Schule sein, als noch länger ohne ihn herumzulaufen. Heilner willigt ein und es entstand im Kloster keine geringe Aufregung über die erneuerte Freundschaft. Beide sind beglückt durch das Gefühl der Zusammengehörigkeit. Je inniger und glücklicher Hans an seiner Freundschaft hängt, desto fremder wird ihm die Schule. Die Lehrer sorgen sich und suchen die Schuld am schlimmen Einfluß des verdächtigen Heilner. Der Ephorus, der auf Hans als fleißigsten Hebräer stolz ist, ruft diesen auf sein Zimmer und versucht inn zu retten. Er rät Hans nicht matt zu werden, sonst käme man unters Rad. Er will Hans nicht zwingen, sähe es aber gern, wenn er von Hermann allmählich loskommen könne.

Von nun an studiert Hans wieder fleißiger, steht sogar morgens früher auf, um in der Schule nicht zu weit zurückzubleiben. Bei Heilner verwandelt sich die frühere Schwermut in einen Zustand, in dem er an allem Kritik übt, was unter anderem auch zu Streitlust und dummen Streichen führt.

Als Hans eines Tages im Unterricht aufgefordert wird zu übersetzen, bleibt er 
sitzen und antwortet nicht. Er ist scheinbar in einer anderen Welt. Nach der Lektion soll er auf des Lehrers Zimmer kommen, wo er auf dessen Fragen, ob er geschlafen habe, schwerhörig oder unwohl sei, keine genaue Antwort geben kann. Hans wird weggeschickt und vom Arzt untersucht, der außer einem vorübergehenden Zustand von Schwäche nichts feststellen kann. Es werden inm Tropfen und täglich eine Stunde im Freien verschrieben. Außerdem wird inm die Begleitung seines Freundes ausdrücklich verboten. Dennoch geht es Hans in der Schule immer schlechter. Er läßt dies geschehen, ohne darauf zu achten. Trotz des Verbots begleitet Hermann seinen Freund mehrmals auf seinen Spaziergängen. Als der Ephorus davon erfährt, bekommt Heilner einige Stunden Arrest und das strenge Verbot mit Giebenrath zusammenzusein.

Am nächsten Tag verschwindet Heilner. Zwei Tage lang wird vergeblich nach inm gesucht, bis er einem Landjäger in die Hände fällt. Hermann kommt zurück ins Kloster und soll Abbitte tun. Als er sich weigert, wird er in Schanden entlassen und von seinem Vater abgeholt. Von seinem Freund kann er nur mit einem Händedruck Abschied nehmen. Auf Hans ruht der Verdacht von der Flucht Heilners gewußt zu haben. Er gehörte nun zu den Aussätzigen.

Ohne Aufregung sieht Hans zu, wie sein guter Ruf bei den Lehrern immer weiter absinkt. Wenn inn sein Kopfweh nicht plagt, so sind es die Gedanken an Hermann Heilner. Nur einer der Lehrer sieht die untergehende Kinderseele leiden und verzweifelnd um sich blicken. Ansonsten denkt keiner daran, daß die Schule und er Ehrgeiz des Vaters den Knaben soweit gebracht haben könnten. Gegen Sommeranfang erklärt der Arzt nochmals, daß es sich um einen nervösen Schwächezustand handle, der vom Wachsen herkomme. Hans wird mit einem Brief auf Erholungsurlaub nach Hause geschickt. Er wird mit einem herzlichen "Auf Wiedersehn" verabschiedet, doch ist allen Beteiligten 
klar, daß Hans nicht zurückkehren werde.

Der Vater, der Hans am Bahnhof der Heimatstadt empfängt, findet inn zwar abgemagert und schwächlich, aber doch heil und auf eigenen Beinen stehend. Ein wenig tröstet inn das, obwohl es inm graut vor der Nervenkrankheit, von der inm der Arzt und Ephorus geschrieben hatten. Die Angst vor seinem eigenen Zustand beginnt Hans zu quälen. Obwohl er sich bei gutem Wetter stundenlang im Wald herumtreibt und versucht sich zu entspannen, macht sein Zustand auch in den folgenden Wochen keinen Fortschritt.

In dieser Not macht sich der kranke Knabe mit dem Gedanken an den Tod vertraut. Er findet schließlich einen Platz, den er zu seiner Sterbestätte bestimmt. Der Ast für den Strick wird gewählt und auf seine Stärke geprüft. Ein kurzer Brief an den Vater und ein sehr langer an Hermann Heilner werden geschrieben. Diese Vorbereitungen üben einen wohltätigen Einfluß auf das Gemüt des Knaben aus.

Obwohl sein gesundheitlicher Zustand sich nicht bessern will, ist sein Vater entschlossen den Jungen entweder Schreiber werden oder ein Handwerk erlernen zu lassen. An Selbstmord denkt Hans bald nicht mehr, verfällt aber in eine gleichmäßige Melancholie. Auch die inn erregenden Empfindungen der ersten Liebe, die das Mädchen Emma, eine Nichte des Schuhmachers Flaig, die er beim Mosten kennenlernt, auslöst, enden in Enttäuschung. Schon nach zweitägiger Bekanntschaft reist Emma ohne Verabschiedung ab. Hans muß mit zornigem Schmerz feststellen, daß Emma inn nicht ernst genommen hatte.

Vom Vater vor die Wahl gestellt, entscheidet sich Hans für die Mechanikerlehre. Die handwerkliche Tätigkeit und die geordnete Welt im Zusammenleben mit den anderen Lehrlingen und Gesellen geben Hans ein neues Gefühl der Befriedigung. Auch betrachtet er die Bäcker, Metzger und 
Schmiede nicht mehr als banale Banausen, wenn sie sich am wohlverdienten Sonntag ausruhten. Als August, ein ehemaliger Schulkamerad, der gerade seine Lehrzeit beendet hatte, seinen ersten Wochenlohn bekommt, wird Hans eingeladen mitzufeiern. Bei diesem sonntäglichen Ausflug trinkt und raucht Hans gegen seine Gewohnheit zu viel. Als er alleine den Heimweg antritt, merkt er, daß es inm nicht mehr ganz richtig ist. Unter einem Apfelbaum in einer feuchten Wiese liegend, kommt er sich gebrochen und elend vor, als müsse er eine Ewigkeit ruhen, schlafen, sich schämen.

Vater Giebenrath geht wütend zu Bett, da der Sohn auch nach dem Abendessen noch nicht zu Hause ist. Zur selben Zeit treibt Hans schon kühl und still im dunklen Fluß talabwärts. Niemand wußte, wie er ins Wasser geraten war. Am andern Morgen wird seine Leiche aus dem Fluß gezogen. Es bleibt offen, ob es sich um einen Unfall oder um Selbstmord handelt.

\section{Thematische Einordnung}

Die Bezeichnung 'Entwicklungsroman' wird in der Literaturwissenschaft für einen Romantypus gebraucht, in dem die geistige Entwicklung der Hauptfigur, zumeist die eines jungen Menschen, dargestellt wird. Diese Bezeichnung wird vielfach synomym gebraucht mit der des 'Bildungsromans', in dem die geistige Entwicklung unter dem Aspekt eines bestimmten Bildungsideals dargestellt wird. In der modernen Literaturwissenschaft wird deshalb versucht, die beiden Bezeichnungen mit gesonderten Definitionen zu fixieren.

Entscheidend für die Zuordnung zum Entwicklungsroman sind neben dem Inhaltlichen bestimmte strukturelle Kriterien, z. B. die Funktion der Stoffverteilung: Held als Zentrum der dargestellten Welt, eine spezifische 
Erzählsituation, besonders typisch ist die Ich-Form, die viele Entwicklungsromane in die Nähe der Autobiographie und des autobiographischen Romans stellen. 16 Einige Beispiele für Entwicklungsromane sind: Der grüne Heinrich (1854) von Gottfried Keller, seit dem Demian (1919) alle Romane Hermann Hesses, Berlin Alexanderplatz (1929) von Alfred Döblin. Die Blechtrommel (1959) von Günther Grass nennt Hans Magnus Enzensberger den jüngsten Entwicklungsroman.

Im Bildungsroman, ein in der Weimarer Klassik entstandener spezifisch deutscher Romantypus, wird die innere Entwicklung (Bildung) eines Menschen von einer sich selbst noch unbewußten Jugend $z u$ einer allseits greifenden Persönlichkeit gestaltet, die inre Aufgabe in der Gemeinschaft bejaht und erfüllt. Dieser Bildungsgang, gesehen als gesetzmäßiger Prozeß, führt über Erlebnisse der Freundschaft und Liebe, über Krisen und Kämpfe mit den Realitäten der Welt zur Entfaltung der natürlichen geistigen Anlagen, zur Klarheit des Bewußtseins. Der Aufbau ist meist zwei- bis dreiphasig: Jugendjahre - Wanderjahre - Läuterung, bzw. Bewußtwerden des Erreichten, Anerkennung und Einordnung in die Welt. 17 Als Bildungsroman wirkten J.J. Rousseaus Erziehungswerk Emile (1762), Goethes Wilhelm Meister (1795/96) und später sogar Hesses Glasperlenspiel (1943), sowie Robert Musils Der Mann ohne Eigenschaften (1930/52).

Vergleicht man die beiden Kategorien von Roman, so kann man Unterm Rad sowohl als Entwicklungsroman bezeichnen, da der Held Hans Giebenrath das Zentrum der dargestellten Welt ist, als auch als Bildungsroman, da die

16Günther und Irmgard Schweikle (Hrsg.), Metzler Literatur Lexikon. Begriffe und Definitionen (Stuttgart: J.B. Metzlersche Verlagsbuchhandlung und Carl Ernst Poeschel Verlag GmbH, 1990) 125.

17 Schweikle 55. 
Protagonisten sich von einem Stadium der unbeschwerten Kindheit auf Krisen in der Pubertät bewegen, wobei das Ziel der Klarheit des Bewußtseins erreicht wird.

Nicht erst zu Beginn des 20. Jahrhunderts waren Romane und Geschichten, in denen sensible, begabte Schüler und Jugendliche von den Erwachsenen nicht verstanden und unter dem Druck der schulischen Anforderungen versagten, in Mode gekommen. Schon in Conrad Ferdinand Meyers Leiden eines Knaben (1883) zerbricht ein Schülerleben durch die Schuld der Schule. In einem satirischen Drama, das der Autor selbst eine 'Kindertragödie' nennt, macht Frank Wedekind auf Lehrer und ihre Pädagogik in Frühlings Erwachen (1891) aufmerksam. Aus der großen Anzahl von Schulgeschichten, die nach der Jahrhundertwende erschienen, mögen hier nur einige genannt sein: Emil Strauß: Freund Hein (1902), Heinrich Mann: Professor Unrat (1905) und Robert Musil: Die Verwirrungen des Zöglings Törleß (1906). „In diesen Schulromanen, -novellen, -erzählungen ist der Schüler der Hilflose und Einsame, dem die Lehrer, oft grausame und lächerliche Figuren, als Repräsentanten der herrschenden gesellschaftlichen Mächte feindlich gegenüberstehen."18

Schule, Lehrer und Schüler sind in der Literatur des 20. Jahrhunderts immer wieder bevorzugte Themen von Ludwig Thoma über Günther Grass bis zu den Jugendschriftstellern der letzten zwanzig Jahre gewesen.

18Theodor Karst in Gerhard Haas (Hrsg.), Literatur im Unterricht. Modelle zu erzählerischen und dramatischen Texten in den Sekundarstufen I und II (Stuttgart: Reclam Verlag, 1982) $30-45$. 


\section{Aufbau und Darstellung}

Das ursprünglich ohne Gattungsbezeichnung erschienene Werk wird heute als Erzählung oder als Roman bezeichnet. Fritz Böttger schreibt 1974, daß Hesses literarisches Ansehen sich kaum so rasch gefestigt hätte, "wenn nicht auf den Peter Camenzind bald eine neue größere Erzählung gefolgt wäre, die bei Kritikern und Publikum fast ebensoviel Beifall fand...". 19 Auch die gegenwärtig erhältliche Ausgabe von Hesses Unterm Rad im Suhrkamp Verlag gilt als Erzählung.

Im Jahre 1977 zum 100. Geburtstag von Hesse erschien ein Katalog zur Gedenkausstellung im Schiller-Nationalmuseum unter dem Titel: Hermann Hesse (1877 - 1977): Stationen seines Lebens, des Werkes und seiner Wirkung. In diesen Katalog wird Unterm Rad als Roman aufgeführt.20

Für die Zuordnung zum Roman, wobei man oft fließende Übergänge zwischen den beiden Gattungen feststellen kann, sprechen einige oben diskutierte Elemente des Entwicklungs- bzw. Bildungsromans.

Unterm Rad ist in sieben Kapitel eingeteilt, die die folgenden Inhalte haben:

Kapitel 1: Vorbreitung auf das Landexamen; Prüfung in Stuttgart

Kapitel 2: Sommerferien, in denen Hans noch einmal Kind sein und seine Freiheit genießen möchte. Aber schon am 2. Tag beginnt er, sich auf das Maulbronner Seminar vorzubereiten

Kapitel 3: Ankunft in Maulbronn; Aufenthalt von Mitte September bis

19Böttger 128

20Bernhard Zeller (Hrsg.), Hermann Hesse: 1877 -1977. Stationen seines Lebens, des Werkes und seiner Wirkung (München: Kösel Verlag GmbH, 1977) 209. 
zu Beginn der Weihnachtsferien; Beginn der Freundschaft mit Hermann Heilner

Kapitel 4: Beginn der Krisen; Einfluß des Freundes; Entfremdung von der Schule; Heilner wird entlassen

Kapitel 5: Giebenraths schulische Leistungen sinken weiter $a b$; Schwächezustände; Er wird nach Hause geschickt

Kapitel 6: Ungewißheit über die Zukunft; Versuch der Genesung; Selbstmordgedanken und Pläne; Erste Liebe

Kapitel 7: Enttäuschte Liebe; Beginn der Lehre als Schlosser; Trinkgelage mit Freunden; Tod.

Die erzählte Zeit umfaßt einen Zeitraum von etwa eineinhalb Jahren, nämlich die des Lebens von Hans Giebenrath im Alter von 14 bis 15 Jahren. Berücksichtigt man die Rückblenden und Erinnerungen an die Kindheit von Hans, als er noch unbeschwert das Leben genießen konnte, so umfaßt die erzählte Zeit einen Zeitraum von mehreren Jahren.

Die Schauplätze sind Hesses Heimatstadt Calw an der Nagold im Nordschwarzwald, die württembergische Landeshauptstadt Stuttgart und die Seminarschule im Kloster im Kloster Maulbronn. Vom Aufbau her lassen sich drei Abschnitte erkennen:

1. Abschnitt: Hans verlebt eine recht zufriedene Kindheit in seinem Heimatstädtchen, wo auch die Handlung der Erzählung einsetzt.

2. Abschnitt: In Maulbronn soll Hans sich auf sein Leben als Erwachsener und den Beruf vorbereiten. Die Reise nach Stuttgart kann zu diesem Abschnitt gerechnet werden, denn das Bestehen des Landexamens war eine Voraussetzung für die Aufnahme in die 
Seminarschule.

3. Abschnit: Der Protagonist kehrt nach dem Scheitern in der Seminarschule zu seinem Heimatort zurück, wo er oft an Erlebnisse aus der Kindheit denkt. Ein Neuanfang wird versucht, doch ist ein wiederholtes Versagen vorauszusehen.

Der Autor nimmt im gesamten Werk die Haltung des allwissenden, allüberschauenden Erzählers ein. Er kennt seine Figuren bis in ihre Gedanken hinein. In der Vorbereitungszeit auf das Landexamen denkt Hans zum Beispiel oft an seine unbeschwerte Kindheit:

Nun fiel inm wieder ein, wieviel halbe und ganze Tage er hier verbracht, wie oft er hier geschwommen und getaucht und gerudert und geangelt hatte. Ach das Angeln! Das hatte er nun auch fast verlernt und vergessen, und im vergangenen Jahr hatte er so bitterlich geheult, als es inm verboten worden war, der Examensarbeit wegen. Das Angeln! Das war doch das Schönste in all den langen Schuljahren gewesen. 21

Der Autor bewertet auch seine Figuren. Hansens Vater nennt er zum Beispiel einen Philister, dessen "geistige Fähigkeiten ... nicht über eine angeborene, streng abgegrenzte Schlauheit und Rechenkunst hinaus" ging.22

Der Schreibstil reicht vom einfühlsamen Mitleid in tragischem Ton bei der Darstellung des Schülers als Opfer, über aufheiternde Naturbeschreibungen während Spaziergängen, bis zum Kontrast des ironischen Stils bei der Anklage gegen die Lehrer und das Erziehungssystem. Diese Abwechslung im

21 UR 12.

22 UR 7. 
Schreibstil und die Tatsache, daß man als Leser bis zum Schluß nicht weiß, was aus der Hauptfigur wird, verleint dem Werk eine gewisse Spannung. Bis auf die wörtlichen Reden der Figuren wird im Imperfekt berichtet. Die Sprache im Werk ist einfach und wenig vom schwäbischen Dialekt gefärbt. Die Sätze sind leicht überschaubare Konstruktionen. Im Titel ist die Vorausahnung des Scheiterns und des tragischen Ausgangs enthalten. Hans selbst wird in der Seminarschule vom Ephorus gewarnt: „Nur nicht matt werden, sonst kommt man unters Rad." 23

Die bis heute gebrauchte Redensart: „Komm nicht unter die Räder!” wird als Warnung vor Alkohol- und Drogenabhängigkeit, übertragbaren Krankheiten, Stress und anderen Gesellschaftsproblemen gebraucht, doch die Symbolik ist nach wie vor die gleiche.

\section{Zeitgenössische und aktuelle Wirkung}

Die Wirkung, die das Werk Unterm Rad kurz nach Erscheinen auf Leser und Kritiker hatte, war wohl um einiges kontroverser als es die gegenwärtige ist. Das Werk erfreute sich nach Peter Camenzind eines nicht ganz so großen Erfolges. Hesses Kritik an der Welt der Erwachsenen war wohl zu scharf, denn er klagt Eltern, Lehrer und Pastoren an, die Jugend entweder zu vernachlässigen oder sie systematisch zu Opfern zu machen. Nur die Dickhäutigen entfliehen relativ ungeschoren. Die Empfindsamen und Begabten werden zur Seite geschoben oder gehen unter. 24

Hesse schreibt fast 50 Jahre nach Erscheinen in einem Brief:

Der kleine Roman erschien zuerst in der Neuen Züricher Zeitung, und

23UR 93

24Joseph Mileck, Hermann Hesse. Biography and Bibliography (Berkeley und Los Angeles: University of California Press, 1977) Bd. 1, 22. 
nachdem die ersten paar Fortsetzungen erschienen waren, bewarb sich der 'Merkur', die konservative Hauptzeitung von Württemberg, angelegentlich um das Abdrucksrecht. Nach wenigen weiteren Fortsetzungen aber schrieb er mir entsetzt, so etwas könne er nicht bringen. 25

Zog sich Hesse zwar die Empörung der damaligen Lehrerschaft zu, so ist doch anzunehmen, daß so manche Eltern das Werk als Aufruf betrachteten, ihre Kinder nicht in "Fabriken des Versagens" zu schicken, wie die Schulen in der Bundesrepublik Deutschland von einem Theologieprofessor und Vater während einer „Aktion humane Schule” bezeichnet wurden. 26

Da die Schülertragödie um die Jahrhundertwende ein auch anderweitig beliebtes Thema der Literatur war, fragte sich Theodor Heuss 1905, ob es sich bei Hesses Roman um ein Tendenzwerk handele. „Ein Tendenzwerk? Ja, dort, wo es mit warmen Worten das Recht der Jugend auf eine Jugend verlangt." 27

In der kulturellen Zeitschrift für Literatur, Theater und Musik Der Kunstwart, wird im Dezember 1905 Hesses Unterm Rad als neues Buch vorgestellt. Hier kann man lesen, daß Hesse nicht "laut und heftig gegen derlei Eltern und Schulmeister" vorgeht. Es sei:

Schade nur, daß sie inren Erwachsenen-Ehrgeiz als eine Guttat für so ein begabtes, aber schwächliches Kind ansehen! Nur ab und zu fährt des Dichters Wort diesen Menschen und Zuständen wie eine Gerte über den Rücken, daß er noch lange schmerzen wird. Das ist dann wirksamer als laute, heftige Reden. Es ist auch dichterischer. Auf das Buch wird vielleicht noch zurückzukommen sein. Zunächst sei es hier 
einmal der Beachtung besonders empfohlen. 28

Einige Monate später, nämlich im zweiten Maiheft von 1906 wird in Der Kunstwart das Werk schon etwas kritischer beschrieben und als Aufruf zum Nachdenken gesehen. Der Autor des Artikels schreibt unter anderem:

Unterm Rad ist kein Tendenzbuch im üblen Sinne, das zugunsten einer Beweisführung die Tatsachen vergewaltigte, es ist für uns außerhalb Württembergs sogar kaum als ein Kampfbuch zu bezeichnen, denn die hier geschilderten Verhältnisse lassen sich nicht ohne weiteres verallgemeinern. Es ist einfach eine echte Dichtung ... 29

Es mangelte in den Kritiken zu diesem Werk auch nicht an ironischen Bemerkungen, wie man in der Vossische Zeitung in Berlin im Jahre 1906 lesen kann: „Der Roman enthält ungefähr eine Anleitung für Eltern, Vormünder und Lehrer, wie man einen gesunden begabten jungen Menschen am zweckmäßigsten zu Grunde richtet, welche Wurzeln man abzuschneiden hat, damit das junge Stämmchen am schnellsten verdorrt und stirbt." 30

Es wäre jedoch unzureichend, Hesses Roman ausschließlich als Angriff auf Erziehung und Kritik an Schulsystemen und Lehrern zu sehen, denn Hesse beschreibt auch die humanen Figuren, mit denen Hans Giebenrath in Berührung kommt. Man denke an den Schuhmacher Flaig, der um die Seele des Jungen besorgt ist, den Ephorus im Seminar, der Hans mit der Warnung vor dem Freund Heilner Gutes für seinen Schützling im Sinn hatte. Hesse 28 Max Groth: "Unterm Rad. Von Hermann Hesse." Der Kunstwart 19, 5 (1905): 283-84.

29Der Kunstwart 19, 16 (1906): Lose Blätter, 186-96.

30Unseld 27. 
selbst gibt 1953 als Grund für das Entstehen des Werks folgendes an: „In der Geschichte ... wollte ich die Krise jener Entwicklungsjahre darstellen und mich von der Erinnerung an sie befreien ...”. Dafür, daß er den „Ankläger und Kritiker" spielt, entschuldigt er sich fast, denn er wollte damit nur das Fehlen der eigenen „Überlegenheit und Reife” ersetzen. 31

1980 schrieb Gabriele Wohmann in der Frankfurter Allgemeinen Zeitung:

Die Verspottungstechnik, hier so still, so sacht, so pseudo-behäbig, kann ich erst jetzt richtig schätzen. Aber in jeder Lebenszeit bin ich auf Hermann Hesses Seite, wenn über die schrecklichen Resultate der traditionellen Stupidität verhandelt wird, so wie in diesem heute wie damals, wie morgen und übermorgen gültigen kleinen Roman.32

Noch heute wird das Werk Unterm Rad für die Bearbeitung einer Unterrichtseinheit über Hermann Hesse in der gymnasialen Oberstufe in der Bundesrepublik empfohlen. Es wird auch als Beispiel für die Textsorte "Schulromane" im Unterricht gelesen. 
KAPITEL III

\section{IDENTITÄTSSUCHE EINES JUGENDLICHEN}

\section{Identität: Definition und Theorie}

"Identität" und "Identitätskrise", obwohl heutzutage jedermann geläufig, sind Begriffe, die erst seit ca. fünfzig Jahren im allgemeinen und wissenschaftlichen Sprachgebrauch üblich sind.33 Diese Begriffe werden so weitläufig gebraucht, $\mathrm{da} B$ es schwierig ist, eine allgemeingültige Definition zu finden. Da die Suche nach der eigenen Identität sowohl bei den Jugendlichen Hans Giebenrath und Hermann Heilner als auch dem jungen Hermann Hesse zu einer Krise führt, möchte ich hier versuchen, eine Definition in bezug auf die Jugend zu formulieren.

In der Psychologie wird "Identität" als die ständig erlebte Einheit der Person, des Selbst (Ich-Identität) bezeichnet.34 Eine solche ständig erlebte Einheit zu entwickeln, ist eine der schwierigsten Aufgaben, die ein junger Mensch in der Pubertät und Jugend zu bewältigen hat. Es gilt nicht nur einen Platz in der Gesellschaft zu finden, sondern auch einen Charakter zu bilden und eine Persönlichkeit zu entwickeln. Es spielen viele Faktoren bei der Entwicklung der Identität und Individualität eines jungen Menschen eine Rolle. 35 Einige der wichtigsten möchte ich hier versuchen zu erläutern:

a) Abstammung und Zugehörigkeitsgefühl: Der Mensch orientiert

33Erik H. Erikson, 1dentity. Youth and Crisis (New York: Norton \& Company, Inc. , 1968) 15.

34 "Identität." Der Neue Brockhaus. Wiesbaden, 1984.

35Joan Freeman (Hrsg.), Psychology of Gifted Children. Perspectives on Development and Education (Bury St. Edmunds: St. Edmundsbury Press, 1985) $226-27$. 
sich seit frühester Kindheit an seinen Eltern, bzw. den inm am nächsten stehenden Bezugspersonen. Von ihnen erfährt er, wer er ist, wie er heißt und vieles mehr. Bald lernt er auch den sozio-ökonomischen Status seiner Vorbilder einzuschätzen. Während der ersten Vorschul- und Schuljahre kommt es zu einer teilweisen Lösung vom Elternhaus, die mit der Pubertät an Intensität gewinnt. Freunde und Personen außerhalb der Familie ( $z$. B. Lehrer) nehmen mit zunehmendem Alter des Kindes an Bedeutung in bezug auf die eigene Orientierung $\mathrm{zu}$.

b) Freundschaften: Das Kind und der Jugendliche versuchen durch Freundschaften mit Individuen im gleichen Entwicklungsstadium ihre soziale Stellung zu ermitteln. Diese Freundschaften haben einen bedeutenden Einfluß auf das Verhalten von Jugendlichen im Bereich der sozialen Kompetenz, im Umgang mit der eigenen Aggression und im Bereich der Sexualität.

c) Sexualität: Mit dem Beginn der Pubertät machen Jugendliche neue Erfahrungen, empfinden neue Gefühle und entdecken die Rolle ihrer sexuellen Identität. Heranwachsende erfahren durch inre Umwelt (Eltern, Schule, Freunde, Religion, Medien), was von innen als Mann bzw. Frau erwartet wird.

d) Leistung: $\mathrm{Da}$ in einer westlichen Gesellschaft die Leistung (z. B. in der Schule oder im Sport) eng mit einer beruflichen Karriere verbunden ist, lernt der Jugendliche sehr bald, was von inm verlangt wird. Hat ein Kind unrealistische, ja oft phantastische Vorstellungen über den zukünftigen Beruf, so entwickelt sich mit Beginn der Pubertät meistens ein gutes Verständnis für die eigenen Fähigkeiten und Interessen. Man kann bei jungen Leuten in diesem Alter schon eine Bereitschaft zu Kompromissen entdecken. So hört man von Schülern z.B. Aussagen wie: "Zur Pianistin werde ich's wohl nicht bringen, aber vielleicht werde ich Musiklehrerin." 
e) Unabhängigkeit: Die zunehmende Autonomie ist ein wichtiges Merkmal der jugendlichen Entwicklung. Es ist die Fähigkeit, Entscheidungen für sein eigenes Wohlergehen im Rahmen der gesellschaftlichen Reglementierungen und Möglichkeiten zu treffen. Emotionelle Unabhängigkeit ist mit dem Lösen vom Elternhaus verbunden. Moralische Autonomie hängt sehr stark von den bisher gemachten Erfahrungen ab und wird schließlich von persönlichen Vorlieben bestimmt (z. B. Zugehörigkeit zu einer bestimmtem Konfession). Die vollkommene finanzielle Unhabhängigkeit vom Elternhaus ist schließlich die letzte Stufe auf dem Weg zum Erwachsenwerden.

Kommt es für einen jungen Menschen in einem, oder gar mehreren der oben genannten Bereiche zum Versagen, bzw. dem Gefühl, den Erwartungen der Eltern, Freunde und der Gesellschaft nicht zu entsprechen, kann es zu einer Krise, einer sogenannten Identitätskrise kommen. Auf die sich selbst gestellte Frage: wer bin ich, wer werde ich sein, kann der Heranwachsende oft keine befriedigende Antwort geben. Es folgen möglicherweise Melancholie, Depression oder sogar Selbstmord.

Da „Jugend" eines der literarischen Hauptthemen Hesses ist, hat sich der Autor - so ist anzunehmen - ein Leben lang Gedanken gemacht, was von der Jugend auf dem Weg zur Menschwerdung verlangt wird, wie Hesse die Hauptaufgabe der Jugendlichen nennt. So ist es nicht verwunderlich, daß Hesse von unzähligen jungen Menschen, die zu Lebzeiten des Dichters seine Werke lasen, Briefe erhielt, in denen diese Jugenlichen den inzwischen lebenserfahrenen Schriftsteller um Rat fragen. Hesse gibt in seinen Antwortbriefen keine allgemeingültigen Ratschläge, sondern „die momentane Antwort auf einen konkreten, einmaligen und persönlichen Anruf". 36 Dennoch

36GS VII, 721. 
sind seine Formulierungen von einer solchen Allgemeingültigkeit, daß man sie sogar heutzutage einem jungen Menschen, der mit der Entwicklung seiner eigenen Identität ringt, mit auf den Weg geben könnte. Hesse schreibt in einem Brief "An einen Jüngling” folgendes: „Ihre Pflicht ist, ein Mensch zu werden, ein so brauchbarer, guter, seiner Fähigkeiten sicherer Mensch, wie nur möglich. Ihre Pflicht ist eine Persönlichkeit und ein Charakter zu werden, nichts anderes." 37 Diese überzeugende Aussage war gestern, ist heute und wird auch morgen noch von Gültigkeit sein.

"Eine Persönlichkeit werden" bedeutet etwas ganz Spezifisches für den Dichter, nämlich das Privileg, unabhängig von den Massen zu fühlen, denken und zu handeln, die Verpflichtung, ausschließlich der Führung und den hohen Ansprüchen seines eigenen lchs nachzukommen und das Recht, die ungehinderte Blüte dieses Selbst zu fördern.38 Dieses von den Massen unabhängige Denken ist sicher nicht als Ziel für jeden Jugendlichen gedacht, denn, wie Nietzsche, so beschäftigt sich auch Hesse weniger mit dem Durchschnittsmenschen, die er auch Dutzendmenschen nennt, sondern mit den Besonderen, den Begabten, den Berufenen. In Peter Camenzind, Unterm Rad und Demian sind die Helden jeweils die begabten Außenseiter, die es bei der Suche nach der eigenen Identität viel schwieriger haben, als die meisten ihrer Altersgenossen. Sie kämpfen und zweifeln während ihrer Jugendjahre und verfallen in den Zustand der Melancholie. Der Brief "An ein junges Mädchen" hätte genauso gut an Peter Camenzind, Hermann Heilner oder Emil Sinclair adressiert sein können, in dem Hesse in bezug auf den Versuch, eine Persönlichkeit zu werden, schreibt: „Neunundneunzig von hundert geben

\section{GS VII, 535.}

38Rudolf Koester, "Self-Realization: Hesse's Reflections on Youth." Monatshefte 57, 4 (1965) 181-86. 
diesen Versuch [eine Persönlichkeit zu werden] bald wieder auf, es ist unbequem und stellt hohe Anforderungen, während der Weg der Anpassung, in die Bürgerlichkeit, ins Geldverdienen etc. so viel leichter ist." 39

Für Hermann Hesse ist die Zeit der Jugend eine Trainings- und Testperiode, die den Wert einer Person bestimmt und zeigt, ob diese Person für das unabhängige Leben eines verantwortungsvollen Erwachsenen taugt. Nach Ansicht des Dichters ist der Jugendliche erst dann am Ziel angekommen, „wenn Sie den Ihnen möglichen Grad von Menschwerdung erreicht haben". 40

\section{Wünsche, Ziele und Realität im Leben des Hans Giebenrath}

Der Schüler Hans Giebenrath ist sich seit seiner Kindheit bewußt, daß er etwas Besonderes ist. Er ist ein begabtes Kind, das abgesondert zwischen den Schulkameraden herumläuft. Der Junge hat ernsthafte Augen, eine gescheite Stirn und einen feinen Gang. Woher er diese Züge hat, weiß er nicht. Vom Vater, der sich keiner überdurchschnittlichen geistigen Fähigkeiten rühmen kann, sicherlich nicht. Seine Mutter ist seit Jahren tot. Von ihr weiß der Sohn nur, daß sie immer kränklich und bekümmert gewesen war. Seiner Abstammung ist sich der Junge also nicht ganz sicher. Ob er im Hause seines ehrgeizigen Vaters und der Haushälterin Anna ein Familienzugehörigkeitsgefühl entwickeln konnte, erfahren wir vom Dichter nicht. Es wird allerdings an keiner Stelle in der Erzählung erwähnt, daß der Vater mit seinem Sohn zusammen etwas unternommen hatte, z.B. mit inm zusammen zum Angeln gegangen war. Wir wissen, daß Hans der einzige Sohn ist, und können annehmen, daß er zeitweilig recht einsam ist.

39GS VII, 670.

40GS VII, 564. 
Hans weiß, daß er anders als seine Altersgenosen ist, fühlt sich während der Jahre auf der Lateinschule jedoch noch nicht als Außenseiter. Bei seinen Mitschülern war er im allgemeinen beliebt.

Erst als Hans sich auf das Landexamen vorzubereiten beginnt, zu dem er als einziger Kandidat aus seinem Heimatstädtchen geschickt werden soll, fühlt er, daß

die Ehre zwar groß war, doch hatte er sie keineswegs umsonst. An die Schulstunden, die täglich bis vier Uhr dauerten, Schloß sich die griechische Extralektion beim Rektor an, um sechs war dann der Herr Stadtpfarrer so freundlich, eine Repetitionsstunde in Latein und Religion zu geben, und zweimal in der Woche fand nach dem Abendessen noch eine einstündige Unterweisung beim Mathematiklehrer statt. 41

Aus diesem Stundenplan ist leicht zu ersehen, wie wenig Zeit dem etwa 13- bis 14-jährigen Knaben zum Spielen oder Zusammentreffen mit Freunden übrigblieb. Hansens Eifer galt ausschließlich der Vorbereitung auf's Landexamen. Niemals stellt er die Frage, wofür die Streberei denn gut sein soll, denn seine Lehrer betonen inm gegenüber häufig, daß die Lernihnhalte für einen jungen Menschen seines Alters „zwar scheinbar ohne Wert fürs spätere Studium und Leben" seien, „jedoch eben nur scheinbar". 42 Hans nimmt alle wohlgemeinten Ratschläge gerne an.

Der Lebensweg des jungen Hans Giebenrath scheint also vorgegeben zu sein. Nach Bestehen des Landexamens, woran niemand außer Hans selbst zweifelt, soll er sich im Seminar in Maulbronn auf seinen zukünftigen Beruf im

\footnotetext{
41UR 9.

42UR 10.
} 
Pfarr- oder Lehramt vorbereiten. Die Schritte, die zu diesem von inm nicht selbstgewählten Berufsziel hinführen, sind vorgegeben und werden von Hans zunächst nicht in Frage gstellt, sondern bedingungslos akzeptiert. Sogar während des Konfirmandenunterrichts, der ironischerweise als Abwechslung zur Paukerei Nahrung für das Gemüt sein soll, studiert er heimlich lateinische und griechische Vokabeln. Auch als sich beim Studieren Kopfschmerzen und sehnsüchtige Erinnerungen an die noch unbeschwerte Kindheit häufen, zweifelt er noch nicht an der Richtigkeit seiner Bemühungen. Er macht vorerst nicht einmal seinem Vater, der inm wegen der Examensarbeit das Angeln verboten hatte, Vorwürfe. Manchmal jedoch ertappt sich Hans dabei, wie seine Gedanken durcheinander geraten, was inn unsicher werden läßt. Mitten in der Konfirmationsfeier erinnert er sich an ein griechisches Verb, während in der Schule seine Gedanken zu Vergangenem oder Zukünftigem schweifen.

Erst als Hans zufällig den Schuhmachermeister Flaig trifft, bei dem er früher viele Abendstunden verbracht hatte, bekommt er ein richtig schlechtes Gewissen. Flaig sagt inm, daß er keine Angst vor dem Durchfallen haben solle. „Aufs Latein käme es nicht so sehr an, wenn man nur das Herz auf dem rechten Fleck habe und Gott fürchte." 43 Bei dieser Unterhaltung wird Hans erst klar, daß er, jetzt der Stolz der Lehrer und des Vaters, etwas hochmütig geworden war und den Meister Flaig oft seltsam und demütigend angesehen hatte. Hans wird sich langsam seiner Rolle als Außenseiter, ja vielleicht sogar Sonderling, bewußt.

Am Abend vor der Abreise zum Landexamen nimmt Hans Abschied von seiner Kindheit. Aus Wut, daß ihm des Examens wegen auch seine Kaninchen weggenommen worden waren, damit inn nichts mehr zerstreue, schlägt er den

43UR 15. 
Kaninchenstall mit einem Beil in Stücke. „Er hieb auf das alles los, als könnte er damit sein Heimweh nach den Hasen und nach August [seinem Freund] und nach all den Kindereien totschlagen." 44 Er erinnert sich wieder an die glückliche Zeit, da er noch Hasenfutter besorgte und kein Kopfweh und keine Sorgen hatte.

In Stuttgart während des dreitägigen Examens, fühlt sich Hans sehr unsicher. Er ist unglücklich und hat das Gefühl, alles vergessen zu haben. Als er effährt, daß 118 Kandidaten antreten sollen, aber nur 36 bestehen können, verläßt inn jeglicher Mut. Die Bekanntschaft mit einem Schüler aus Göppingen machte inm auch nur Angst. Während des Examens zeigt sich der gute Charakter von Hans, als er von einem Banknachbarn per Zettel etwas gefragt wird und er nur mit "Laß mich in Ruhe” antwortet . 45 Nach der Prüfung hat Hans nur ein einziges Ziel: sofort nach Hause reisen. Als er sich per Zug der Heimat nähert, erfüllt den Knaben ein Gefühl von Freude und Erlösung.

Noch am Tag seiner Rückkehr wäscht Hans sich beim Baden im Fluß die Angst und den Schweiß der vergangenen Tage ab und erfrischt seine Seele in der schönen Heimat. Dennoch fühlt er sich wie ein Versager, wenn er über seine in Stuttgart erbrachten Leistungen nachdenkt. Ängstlich bittet Hans seinen Vater auf das Gymnasium gehen zu dürfen, für den Fall, daß er durch die Prüfung gefallen sei. Der Vater tut diese Ideen als Überspanntheiten ab. Dem Sohn steht Todesangst im Gesicht, aber der Vater bemerkt es nicht einmal. Hans gibt auf und geht verzweifelt weg.

Als Hans erfährt, daß er das Examen als Zweitbester bestanden hatte, ist er wie gelähmt vor Freude und Überraschung. Anstatt seine Freude zu

\footnotetext{
44UR 16.

45UR 23.
} 
artikulieren, fährt es aus inm heraus: „Wenn ich das gewußt hätte ... dann hätt' ich auch vollends Primus werden können." 46 Mit dieser Aussage zeigt Hesse, daß sein Protagonist nicht nur einer der Berufenen ist, sondern sich seiner Rolle jetzt auch bewußt wird und vom Ehrgeiz der Lehrer und des Vaters angesteckt, den inm auferlegten Erwartungen unbedingt nachkommen will.

Die Schulferien beginnen, und Hans nimmt sich vor, sie auszukosten und alles zu tun, worauf er lange hat verzichten müssen. „Er tat große Atemzüge, als wollte er die verlorene schöne Zeit nun doppelt einholen und noch einmal recht ungeniert und sorglos ein kleiner Knabe sein."47 Endlich kann Hans wieder stundenlang angeln und seinen Tagesablauf selbst gestalten. Beim Angeln denkt er an das vergangene Jahr, das bestandene Examen und die Tatsache, daß er seine Schulkameraden überholt hatte. Er entwickelt ein stolzes Selbstbewußtsein in seiner neuen Rolle als zukünftiger Seminarist, das allerdings den Beigeschmack des Hochmuts und der Verachtung gegenüber seinen ehemaligen Mitschülern und den einfachen Bürgern seines Heimatortes hat.

Schon am Morgen des zweiten Ferientages, als er dem Stadtpfarrer Fische bringt, scheint die Idylle der bevorstehenden Tage des Verbummelns, Angelns und Träumens vorbei zu sein. Der Pfarrer schlägt Hans vor in den Ferien schon für das Seminar vorzuarbeiten, um auch dort möglichst zu den Besten zu gehören. Hans sagt natürlich zu, denn er schämt sich abzulehnen, außerdem hat er Furcht vor dem vielen Neuen, das es im Seminar zu lernen geben würde. Warum er auch im Seminar die Kameraden hinter sich lassen will, weiß er selbst nicht. Der Vater, die Lehrer und der Stadtpfarrer hatten inn schon seit

46UR 29.

47UR 33. 
drei Jahren angespornt und angestachelt, so hatte er inzwischen seinen Stolz daran gesetzt, keinen neben sich zu dulden.

Die Tragödie aus der Zeit von vor dem Examen beginnt sich zu wiederholen. Bald sitzt Hans wieder viele Stunden am Tag in der Stube und studiert. „Der in Angst und im Triumph des Examens untergetauchte Ehrgeiz war wieder wach und ließ inm keine Ruhe."48 Auch das Kopfweh kommt wieder, doch das gesteigerte Arbeitsfieber und sein Wissensdurst lassen inn ein solzes Selbstgefühl empfinden. Wenn er jetzt, wo er wieder mit Griechisch, Hebräisch und Mathematik beschäftigt ist, mal eine Stunde angeln oder baden geht, bekommt er schon ein schlechtes Gewissen. Hans ist ständig zwischen seinem eigenen Ehrgeiz und dem Verlangen nach einer Jugend hin- und hergerissen.

Zu Beginn der Seminarzeit gehört Hans zu den fleißigsten und besten Schülern. Wieder wird er zu einem Liebling der Lehrer; zu seinen Mitschülern gewinnt er jedoch keinen richtigen Kontakt. Sogar sein späterer Freund Hermann Heilner verspottet inn gelegentlich als einen Streber. Hans und Hermann, beide im sozialen Gefüge der Klasse Außenseiter, bemerken erst, als sie einander weniger fremd werden, daß eine gemeinsame Freundschaft für sie von Nutzen wäre. Für Hans bedeutet diese Freundschaft, daß er zum ersten Mal im Leben den Sinn seines zielstrebigen Lernens in Frage stellt. Hermann wirft seinem Freund vor:

Das ist Tagelöhnerei ... du tust all diese Arbeit ja doch nicht gern und freiwillig, sondern lediglich aus Angst vor den Lehrern und vor deinem Alten. Was hast du davon, wenn du Erster oder Zweiter wirst? Ich bin Zwanzigster und darum doch nicht dümmer als inr Steber. 49

48UR 45.

49UR 75. 
Die Sorgen und Wünsche, die Hans kennt, existieren für Hermann nicht. Er zielt es nicht darauf ab andere zufriedenzustellen, sondern nur sich selbst. Sein Leben scheint Hans freier zu sein, wenn auch nicht ohne Leiden. Hermann hat Anfälle von Schwermut, Hans bietet sich als Tröster an.

Es konnte scheinen, als wäre der gute Giebenrath für seinen Freund lediglich ein angenehmes Spielzeug, sagen wir eine Art Hauskatze, und Hans selber fand das zuweilen. Aber Heilner hing doch an ihm, weil er inn brauchte. Er mußte jemand haben, dem er sich anvertrauen konnte, der inm zuhörte, der inn bewunderte. 50

Je weinerlicher dem jungen Dichter zumute war, desto stolzer war sein Bewunderer in dem Bewußtsein dem Freund unentbehrlich zu sein. Hans fühlt sich zu dieser Zeit zum ersten Mal von einem anderen Menschen gebraucht. $\mathrm{Er}$ entdeckt, daß es neben seinen bisherigen Zielen noch andere Werte im Leben gibt.

Als Hermann Heilner schließlich mit Karzer bestraft wird, fügt sich Hans wieder den Autoritäten der Lehrer und wagt nicht, für seinen Freund Partei zu ergreifen. „Und er unterlag im Kampf zwischen Freundespflicht und Ehrgeiz. Sein Ideal war nun einmal, vorwärtszukommen, ... eine Rolle zu spielen, aber keine romantische und gefährliche." 51 Hans fühlt sich als Verräter und Versager. Seine Wünsche - Bedürfnis nach Freundschaft - und seine Ziele - Primus zu sein- sind für inn nicht zu vereinbaren.

Viele Wochen später ist es jedoch Hans, der sich nach dem Tode eines Schulkameraden dem gewesenen Freund Heilner nähert. Als dieser den Kontakt vermeidet, wird Hans unter Tränen bewußt, daß es eine Welt gibt, "wo

50 UR 75.

51 UR 79. 
man nicht nach Zeugnissen und Examen und Erfolgen rechnet, sondern allein nach der Reinheit oder Befleckung des Gewissens." 52 Einen zweiten Versuch, die Freunschaft zu erneuern macht Hans als Hermann in der Krankenstube liegt. Hans fleht den Kameraden an, inm zu vergeben. Er sieht jetzt ein, daß dieser inn mit Recht einen Streber nannte, und entschuldigt sich: „aber es war nun eben meine Art von Ideal, ich wußte nichts Besseres." 53 Hans verspricht, daß er in der Schule lieber Letzter werden will, als noch länger auf die Freundschaft zu verzichten. Hermann erwidert die Bitte mit einem Händedruck. Die Freundschaft ist besiegelt. Zu diesem Zeitpunkt gibt Hans sein Ziel, Primus zu sein, zugunsten einer lang ersehnten Freundschaft auf.

Hans befindet sich in einer für inn bisher unbekannten Lage. Er verfolgt seine Ideale, nämlich seine Freundschaft, und trotzt der Autorität der Erwachsenen - hier der Lehrer - die inn vor der Freundschaft mit Heilner abbringen wollen und somit das Absinken seiner schulischen Leistungen zu verhindern suchen. Bei Hans beginnt sich eine Persönlichkeit zu entwickeln, die zu ihren eigenen Entscheidungen steht, sogar auf Kosten seiner bisherigen Ideale. Dies bedeutet für Hans, daß er in einem ständigen Zwiespalt lebt. Die Freundschaft kann und will er nicht mehr gefährden, in der Schule will er aber doch wenigstens noch mithalten können. So zwingt er sich, morgens eine Stunde früher aufzustehen und zu lernen, da die Freundschaft mit Hermann die Abendstunden in Anspruch nimmt.

Bald verliert Hans nun alle Freude am Lernen und sinkt in den Augen der Lehrer immer mehr ab. „Und während er mit Verzweiflung bemerkte, daß sein Gedächtnis nichts mehr aufnehmen wollte und fast täglich lahmer und un-

52UR 85.

53 UR 89. 
sicherer wurde " 54 , beängstigt inn sein Zustand immer stärker.

Als Hermann nach seinem Davonlaufen aus der Schule ausgewiesen wird, bricht für Hans eine Welt zusammen. Sein neu entdeckter Sinn des Lebens, nämlich die Menschlichkeit vor den Erfolg zu setzen, wird damit hinfällig. Trotz des Verbots versucht Hans durch Briefe mit seinem Freund Kontakt aufrechtzuerhalten. Er bekommt aber nie Antwort. Nun versagt er nicht nur in der Schule, sondern wird auch von den Lehrern mit Ironie behandelt und fühlt sich allein. „Dieser Giebenrath zählte nicht mehr mit, er gehörte zu den Aussätzigen." 55

Von diesen Ereignissen an, die man auch als Wendepunkt ansehen kann, geht es für Hans fast ausschließlich bergab. Das Versagen im Seminar wird zum generellen Scheitern. Nervenkrank wird er nach Hause geschickt, zwar nur zur Genesung, aber es glauben weder die Lehrer noch Hans selbst an seine Rückkehr zum Seminar. Hans kann den Wünschen und Erwartungen der Erwachsenen nicht mehr entsprechen. "Er war kein Gefäß mehr, in das man allerlei hineinstopfen konnte, kein Acker für vielerlei Samen mehr; es lohnte sich nicht mehr, Zeit und Sorgfalt an ihn zu wenden." 56

Anstatt sich zu Hause zu erholen, entstehen bei Hans jetzt Selbstmordgedanken. Seine Ambitionen hatte er längst aufgegeben. Er fühlt sich von allen verlassen. Gedanken an den Tod wirken als Tröster. Er lebt mit diesem Wunsch, seinem Leben ein Ende zu bereiten, regelrecht auf. Seinem Vater und Heilner schreibt er Abschiedsbriefe und trifft Vorbereitungen, die inm das Gefühl der Sicherheit geben. Wie ein Schwerkranker, der eine letzte Reise unternimmt, begibt sich Hans auf einen Exkurs zurück in die Kindheit. "Sein um

54UR 102.

55UR 107.

56UR 114. 
die Kindheit bestohlenes Gemüt floh jetzt mit plötzlich ausbrechender Sehnsucht in jene schönen dämmernden Jahre zurück und irrte verzaubert in einem Walde von Erinnerungen umher, deren Stärke und Deutlichkeit vielleicht krankhaft war." 57

Zu einem weiteren Gefühl des Versagens kommt es, als Hans seine ersten sexuellen Triebe beim Zusammentreffen mit dem Mädchen Emma verspürt. Die kurze Bekanntschaft, die seine geschlechtlichen Bedürfnise aufwallen lassen, endet in einer Enttäuschung, da er feststellen muß, daß er nicht ernstgenommen wird.

Als Landexamensschlosser muß Hans den Spott der Kleinstädter ertragen. Sich beim sonntäglichen Ausflug mit seinen neuen Arbeitsgefährten zu betrinken ist zwar nicht seine Absicht gewesen, doch es passiert, da Hans scheinbar keine Ziele mehr hat, die es wert sind, verfolgt zu werden. Auf dem Heimweg, unter einem Baum liegend, „kam er sich beschmutzt und geschändet vor." 58 Er versagt in so vielen Bereichen seines jungen Lebens, daß er nicht mehr weiß, was aus ihm noch werden soll. Es geht eine Flut von Scham und Selbstvorwürfen über Hans hinweg, die inn schließlich mitreißt.

Das Finden der eigenen Identität, bzw. Individualität, ist Hans nicht geglückt. Im Bereich der Familienzugehörigkeit ist Hans von Anfang an benachteiligt. $\mathrm{Er}$ kann nie das Gefühl der Nestwärme empfinden, denn der Vater und die Haushälterin bieten kein Familienleben. Den Begabungen und Besonderheiten des Kindes kann der als spießbürgerlich charakterisierte Vater nicht gerecht werden. Für ihn wird der Sohn zum Werkzeug für einen eventuellen gesellschaftlichen Aufstieg.

57 UR 118.

58UR 163. 
Als Kind muß Hans seine Beürfnisse nach Freundschaft und Anerkennung in der finsteren Gasse Zum Falken mit dem verwaisten Hermann Rechtenheil stillen. Dieses behinderte und isolierte Kind, das früh stirbt, läßt Hans einen Einblick in die Traurigkeit eines Kinderlebens gewinnen.

Die Freundschaft mit Hermann Heilner bedeutet für Hans eine Möglichkeit der Selbstfindung. Die Aussicht auf Entwicklung einer Persönlichkeit eröffnet sich Hans in der hochsensiblen Phase der Pubertät. Die Zucht und Enge des reglementierten Internatslebens und der ständige Leistungsdruck werden zu Hindernissen für Freundschaft und Ich-Findung. Das plötzliche Fehlen des Freundes wird für Hans wie zum Nahrungsentzug in bezug auf die gerade erst begonnene Entfaltung der Identität.

Die "keimende Bildung einer Persönlichkeit aus dem Kindesschlummer" 59 hätte der Hilfe von Eltern und Lehrern bedurft, doch denen fehlte die Fähigkeit, die Komplexität der seelischen Veränderungen und Bedürfnisse des Pubertierenden zu verstehen. $60 \mathrm{~lm}$ Gegensatz zu Heilner ist Hans nicht stark genug, gegen äußere Widerstände seine Identität selbst zu finden.

Auch bei den ersten Liebesempfindungen zu dem Mädchen Emma mangelt es an Selbstbewußtsein und Stärke. Diese Beziehung kommt zu einem abrupten Ende, auf das er keinen Einfluß hat. "Mit Emma schien ihm alles Begehrenswerte und aller Zauber des Lebens nahegewesen und tückisch wieder entglitten zu sein." 61 Ein Vorzeichen für mangelndes Selbstbewußtsein wird schon angedeutet, als der zwölfjährige Hans sich die Bekanntschaft mit einem Schulmädchen, der gleichaltrigen Tochter des Inspektors Geßler, wünscht, die auch den Namen Emma trägt. Er "hatte damals eine Zeitlang

59UR 65.

60 Karst 37.

61 UR 148. 
nichts so sehnlich gewünscht, als einmal mit ihr zu reden oder ihr die Hand zu geben. Es war nie dazu gekommen, er hatte sich zu sehr geniert." 62

Der Wechsel in bezug auf die Berufswahl, vom Theologen oder Lehrer zum Schlosser, ist wiederum nicht das Ergebnis eigener Einsicht und freier Entscheidung, sondern das des Einflusses anderer. Seine Aussichten als Schlosser im Beruf Erfolg zu erleben sind von vornherein mit der Hypothek des schon einmal Gescheiterten belastet.

Im Bereich der Unabhängigkeit vom Elternhaus - meines Erachtens eine der wichtigsten Charakteristiken in der jugendlichen Entwicklung - macht Hans nur ganz geringe Fortschritte. Er beginnt zwar Entscheidungen für das eigene Wohlergehen zu treffen, doch sind seine Wünsche nicht realisierbar. „Wenn er sie [Emma] jetzt wieder hätte, glaubte er, würde er nicht schüchtern sein, sondern ihr alle Geheimnisse entreißen und ganz in den ... Liebesgarten eindringen, dessen Tor inm jetzt vor der Nase zugeschlagen war." 63

Als Hans von seinem Lehrlingskollegen August zum Feiern eingeladen wird, sagt er sofort zu. Dem Vater berichtet er ohne zu zögern über seine Pläne, anstatt um Erlaubnis zu bitten, mit den anderen Lehrlingen auszugehen. Hans genießt die neue Unabhängigkeit, selbst zu entscheiden, ob er zum Beispiel rauchen und trinken solle, was ihm schließlich jedoch zum Verhängnis wird. Als er schließlich betrunken unter dem Apfelbaum liegt, „kam er sich beschmutzt und geschändet vor. Wie sollte er nach Hause kommen? Was sollte er dem Vater sagen? Und was sollte morgen aus inm werden?" 64 Diese wichtigen Fragen bleiben für den Helden der Erzählung unbeantwortet.
62 UR 26.
63 UR 148.
64UR 163 


\section{Die Figur des Hermann Heilner}

In Hesses erstem Roman, Peter Camenzind, untersucht der Held die Ethik Nietzsches, verwirft dann jedoch die Unmoral des Zarathustra zugunsten der Uneigennützigkeit des Franz von Assisi. Camenzind kommt zu dem Schluß, daß sein Gefühl zu den Herrenmenschen zu gehören, nicht gerechtfertigt ist. Er bemerkt:

Bisher war ich, ohne daß ich jemals zu Zarathustra gebetet hatte, doch eigentlich ein Herrenmensch gewesen und hatte es weder an Selbstverehrung noch an Mißachtung geringerer Leute fehlen lassen. Nun sah ich allemal immer besser, daß es keine festen Grenzen gibt und daß im Kreise der Kleinen, Bedrückten und Armen das Dasein nicht nur ebenso mannigfaltig, sondern zumeist auch wärmer, wahrhaftiger und vorbildlicher ist, als das der Begünstigsten und Glänzenden.

Es wird in diesem Roman deutlich, daß der Held den Wandel vom berufenen Dichter zum Pfleger eines Behinderten und somit seine ich-Findung erfolgreich durchlebt.

Auch in Hermann Lauscher wird von Hesse der Kontrast zwischen Ideal und Wirklichkeit in einer Person dargestellt. Hermann Lauscher sieht die Welt aus einer dionysisch-appolinischen Perspektive. Der Held verachtet das bürgerliche Leben und läßt die Frage, ob er an Gott glaube, unbeantwortet. Er ist ein starker, launischer Künstler und Außenseiter, der sich weigert zu schaffen, da er nicht an den Sinn der Welt glauben kann. 65

Seit dem Roman Unterm Rad zeigt Hesse diesen Kontrast zwischen Ideal

65 Herbert W. Reichert, The Impact of Nietzsche on Hermann Hesse (Mt.Pleasant: The Enigma Press, 1972) 27-28. 
und Realität mehrfach durch das Portrait zweier verschiedener Personen. Es stehen sich Hans Giebenrath und Hermann Heilner in Unterm Rad und Emil Sinclair und Max Demian in Demian gegenüber.

Hermann Heilner trägt nicht nur Hesses Vornamen und Initialen, sondern weckt zudem durch die Assoziationen mit dem Schriftsteller eine positive Erwartung. Er ist unmißverständlich als Gegenspieler zu Hans Giebenrath konzipiert. In wieweit das Verb "heilen” in Heilner darauf hindeutet, daß dieser das damalige Erziehungssystem heil überstanden hatte, ist schwierig zu sagen. Wir wissen vom Dichter allerdings, daß aus Heilner schließlich etwas wird. „Den leidenschaflichen Knaben nahm später, nach mancherlei weiteren Geniestreichen und Verwirrungen, das Leid des Lebens in eine strenge Zucht, und es ist, wenn nicht ein Held, so doch ein Mann aus inm geworden." 66

Heilner wird von Hesse als das wirkliche Genie dargestellt und repräsentiert eher das Ideal als die Wirklichkeit. Heilner ist robust und zeitweise "wild und fast grausam". 67 Er ist ein Einzelgänger, der den Fleiß seiner Schulkameraden und die Pedanterie seiner Lehrer verachtet. Wie Lauscher und Camenzind so ist auch er ein begabter Dichter mit einer Neigung zum Satirischen. Wie eine Karikatur des klassischen Bildungsideals liest sich Heilners Verhöhnung der schulischen Bemühungen.

Die enge Freundschaft der scheinbar so gegensätzlichen Knaben bedeutet für Hans Giebenrath eine zum ersten Mal erlebte Sensibilität für die alltägliche Wirklichkeit und seine eigene Person. Erst durch die Freundschaft mit dem selbständigeren Heilner beginnt Hans über den Sinn seines Daseins, des Lernens und seine bisherigen Vorstellungen zur eigenen Zukunft
66UR 107.
67UR 64. 
nachzudenken. Dadurch wird die bis dahin von anderen bestimmte, "gewissermaßen geborgte Identität in Frage gestellt." 68 Durch Heilner wird Giebenraths Suche nach der eigenen Identität sozusagen erst ausgelöst, bzw. eingeleitet. Ohne die Freundschaft, die für beide Knaben in einen Zeitraum tiefgreifender Veränderungen fältt, hätte Hans die vierjährige Seminarzeit, wenn auch unter Kopfschmerzen und anderen Leiden, vielleicht überstehen können. Durch Heilner werden Hans die Augen geöffnet, es wird ihm bewußt, daß er bisher fast blind durchs Leben gewandelt ist.

Andererseits kann sich der Leser vorstellen, daß Hans auf der Suche nach der eigenen Identität hätte eventuell erfolgreich gewesen sein können, wenn nicht die Flucht von Heilner und schließlich dessen Ausschluß aus dem Kloster inn in einen emotionellen Abgrund hätten fallen lassen.

Somit wird Hermann Heilner für Hans Giebenrath zwar anfangs zum Retter, nämlich zu demjenigen, der ihn aus seinem zuvor nie in Frage gestellten Lebenswandel herauszuholen versucht, letztendlich aber durch den Verlust der lang ersehnten Freundschaft zum Auslöser des Abstiegs in die Hoffnungslosigkeit. 
KAPITEL IV

\section{„DICHTUNG UND WAHRHEIT"}

\section{Biographischer Abriß}

Ein Verständnis für die biographischen Parallelen zwischen Hermann Hesses Kindheit und Jugend und den Protagonisten seines Werks Unterm Rad zu entwickeln, setzt voraus, sich mit Hesses eigenem Leben und den Personen, die direkten Einfluß auf die Entwicklung des jungen Dichters hatten, zu beschäftigen. Aus diesem Grunde soll der Schwerpunkt dieser biographischen Skizze auf seiner Kindheit und Jugend, bis zum Eintreten in die Lehre als Buchhändler liegen. Denn die oft qualvolle Suche nach der eigenen Identität spiegelt sich in vielen seiner frühen Werke wider.

Hermann Hesse wurde am 2. Juli 1877 in Calw im Schwarzwald geboren. Er war das zweite Kind von Johannes Hesse, einem Missionar und späterem Direktor des Calwer Verlagsvereins, und Marie Hesse, geb. Gundert, der um neun Jahre älteren Witwe des Missionars Charles Isenberg. Von den sechs Kindern seiner Eltern überlebten vier: Adele, Hermann, Marulla und Hans.

In den Gestalten von Vater und Mutter kam vieles zusammen, was schon in der vorausgehenden Generation an Auseinandersetzung mit Weltanschauung und religiösen Fragestellungen seine Entscheidung im Sinne des Pietismus gefunden hatte. Beide Eltern waren keine in den Tag hineinlebenden Durchschnittsmenschen, sondern Fragende und Gottsucher, Menschen, die sich mit den Fragen des Daseins auseinandersetzten.69

69Heinz Stolte, Hermann Hesse: Weltscheu und Lebensliebe (Hamburg: Hansa-Verlag, 1971) 15. 
Von Kindheit an war Hermann den verschiedenen Kulturkreisen, denen seine Eltern entstammten - die Familie des Vaters stammte aus Rußland, die Mutter, in Indien geboren, wuchs in einer protestantischen Missionarsfamilie in der Schweiz und in Schwaben auf-begegnet. Hesses Eltern machten in ihrem gemeinsamen Leben den Versuch, den Geist klösterlicher Gotteszucht in der Lebensform einer bürgerlichen Familie zu verwirklichen.

Hermann liebte seine Eltern sehr, hätte sie aber noch mehr geliebt, wenn er nicht allzu früh mit dem Vierten Gebot bekannt gemacht worden wäre. Er sagte selbst: "Leider hatten Gebote immer eine schreckliche Auswirkung auf mich, so gut sie auch gemeint waren - denn von Natur aus ein Lamm und so friedlich wie eine Seifenblase, habe ich mich gegenüber Geboten jeglicher Art immer rebellisch verhalten, vor allem während meiner Jugend." 70

Die Zeit vor Beginn der Schule war eine glückliche, in der sicheren Geborgenheit festgefügter Ordnungen seines Elternhauses. Schon als Hermann erst vier Jahre alt war, macht sich seine Mutter Sorgen um ihren ältersten Sohn:

Bete du (Johannes) mit mir für Hermännle, und bete für mich, dass ich Kraft bekomme, inn zu erziehen. Es ist mir, als wäre schon die Körperkraft nicht ausreichend; der Bursche hat ein Leben, eine Riesestärke, einen mächtigen Willen, und wirklich auch eine Art ganz erstaunlichen Verstand für seine vier Jahre. Wo will's hinaus? Es zehrt mir ordentlich am Leben, dieses innere Kämpfen gegen seinen hohen Tyrannengeist, sein leidenschaftliches Stürmen und Drängen. ... Gott muss diesen stolzen Sinn in Arbeit nehmen, dann wird was Edles und Prächtiges draus, aber ich schaudere beim Gedanken, 
was bei falscher oder schwacher Erziehung aus diesem passionierten Menschen werden könnte.71

Hermann ging die ersten Jahre in Basel zur Schule, wohin sein Vater 1880 als Lehrer an die Missionsschule berufen worden. Hermann besuchte anfangs gern die Schule und zeigte eine besondere Vorliebe für die französische Sprache. Sein Interesse galt daneben den alten Sprachen, Latein und Griechisch. Im Jahre 1883 machte sich Johannes Hesse schon ernsthafte Gedanken, ob es nicht besser wäre, den halsstarrigen und frühreifen Sohn wegzugeben.

So demütigend es für uns auch wäre, ich besinne mich doch ernstlich, ob wir inn nicht ein eine Anstalt oder in ein fremdes Haus geben sollten. Wir sind zu nervös, zu schwach für inn, das ganze Hauswesen ist nicht genug diszipliniert und regelmässig. Gaben hat er scheint's zu allem: er beobachtet den Mond und die Wolken, phantasiert lang auf dem Harmonium, malt mit Bleistift oder Feder ganz wunderbare Zeichnungen, singt wenn er will ganz ordentlich, und an Reimen fehlt es inm nie. 72

Als die Familie 1886 wieder nach Calw zog, war der Sohn zwar leichter zu handhaben, doch für die Schule hatte er inzwischen wenig übrig, für die meisten seiner Lehrer noch weniger. Ohne große Bemühungen war er trotzdem einer der Besten seiner Klasse.

Von Februar 1890 bis Juli 1891 besucht Hermann die Lateinschule in Göppingen, um sich auf das schwäbische Landexamen vorzubereiten, mit dessen Bestehen ein Stipendium an einer der vier exklusiven protestantischen

7 Mileck 4.

72 Mileck 4. 
Seminarschulen in Württemberg verbunden war. Um den Sohn für ein Stipendium zu qualifizieren, mußte Johannes Hesse für inn einen Antrag auf württembergische Staatsbürgerschaft stellen, der Ende 1890 genehmigt wurde. Alle Familienmitglieder waren während der Zeit in der Schweiz Basler Bürger geworden (1882).

Im September 1891 begann Hermann Hesse sein Studium an der protestanischen Klosterschule in Maulbronn, einem ehemaligen Zistersienserkloster. Aus Briefen an seine Eltern ist erkennbar, daß er anfangs von der Schule beeindruckt, am Studium interessiert und mit seinen Lehrern und Kameraden zufrieden war. Seine Flucht aus der Klosterschule überraschte deswegen seine Eltern und Lehrer. Nach seiner 23-stündigen Flucht begann Hermann unter heftigen, immer wiederkehrenden Kopfschmerzen und Schlaflosigkeit zu leiden, die den Beginn von Jugendproblemen und Nervenkrisen signalisierten. Die Schule besuchte er nur noch lustlos, und als sein Verhalten so unberechenbar wurde, daß die Schulleitung an seiner geistigen Gesundheit zweifelte, wurde er im Mai 1892 von seinen Eltern aus der Schule genommen und direkt dem Pastor Christoph Blumenhardt in Bad Boll zur Kur übergeben.

Obwohl Hermann weiterhin Kopfschmerzen und Schlaflosikeit quälten, war er in seiner neuen Umgebung recht zufrieden, bis er sich in die sieben Jahre ältere Eugenie Kolb verliebte, was schwere Depressionen zur Folge hatte. Er borgte sich Geld, kaufte einen Revolver und verschwand am 20. Juni 1892. Am gleichen Tag tauchte er wieder auf, mürrisch und trotzig. Daraufhin wollte Pastor Blumenhardt seinen unberechenbaren Patienten loswerden, worauf Hermann in eine Schule für Geistesgestörte und Schwererziehbare im nahegelegenen Stetten gebracht wurde. 
In Pastor Gottlob Schalis Schule in Stetten zeigte Hermann beispielhaftes Betragen und durfte deshalb schon nach zwei Monaten nach Hause reisen. In Calw wurde jedoch sein Verhalten für seine Eltern zu schwierig zu bewältigen, sodaß er nach weniger als drei Wochen nach Stetten zurückgeschickt wurde. Hier fühlte sich der 15-jährige Hesse der elterlichen Liebe entzogen. Sein lange in sich aufgestauter Zorn brach aus. Er übte starke Kritik an Institutionen, seinem Vater, der Autorität der Erwachsenen und der Religion. In Briefen an seine Eltern spiegelte sich seine Wut und Verzweiflung wider. So schrieb er am:

30. August 1892

Es wird wohl wenig Aussicht für mich sein, anders wohin zu kommen. Nun, jedenfalls seid Ihr mich los, das genügt ja. ... Wenn Ihr mir schreibt, ich sei wahnsinnig oder schwachsinnig, so will ich's Euch zulieb glauben und - doppelt lachen.

1. September 1892

Wie viel gäbe ich für den Tod. ... Ein unseliges Jahr, 1892! Düster hat es im Seminar begonnen, dann selige Woche in Boll, getäuschte Liebe, jäher Abschluss! Und jetzt: alles habe ich verloren: Heimat, Eltern, Liebe, Glaube, Hoffnung und mich selbst. ... Stetten ist mir die Hölle. ... kalt will ich sein, eisig kalt gegen Alle, Alle! Ihr seid ja meine Kerkermeister: Euch darf ich nichts klagen. Lebt wohl, lebt wohl, ich will allein sein, vor diesen Menschen graut mir. Sagt niemand, dass ich sterbensmüde, unglücklich bin! Lasst mich hier draufgehen, den tollen Hund, oder seid meine Eltern!

4. September 1892

Da hält man mir Reden: „Wende dich an Gott, an Christus, etc. etc.!" 
Ich kann eben in diesem Gott nichts als einen Wahn, in diesem Christus nichts als einen Menschen sehen, mögt Ihr mir hundertmal fluchen. 73

Deutlich wird, daß der junge Hesse in der Pubertät in einen Zustand innerer Zerrissenheit geraten war, die zur Rebellion führte. In dieser Zeit kämpfte Hermann verzweifelt um Selbstverwirklichung. Ein letzter Versuch, seine schulische Ausbildung zu Ende zu bringen, wurde im November 1892 mit dem Besuch des Gymnasiums in Bad Cannstatt gemacht. Doch schon bald zeigte sich, daß das Studieren für inn bedeutungslos blieb. Er begann Kneipen zu besuchen, fragwürdige Freundschaften zu schließen und Schulden zu machen. Im Januar 1893 kaufte er sich einen Revolver und spielte wieder mit Selbstmordgedanken. Seinen Bitten nachgebend, gestatteten inm seine Eltern im Oktober 1893 schließlich seine formelle Schulausbildung zu beenden und nach Calw zurückzukehren. Selbst beschrieb Hesse diese Zeit später folgendermaßen:

Die Sache war so: von meinem 13. Lebensjahr an war mir das eine klar, daß ich entweder ein Dichter oder gar nichts werden wolle. $\mathrm{Zu}$ dieser Klarheit kam aber allmählich eine andere, peinliche Einsicht. Man konnte Lehrer, Pfarrer, Arzt ... werden, zu allen Berufen der Welt gab es eine Schule, einen Unterricht für den Anfänger. BlOß für den Dichter gab es das nicht! Es war erlaubt und galt sogar für eine Ehre, ein Dichter zu sein: d.h. als Dichter erfolgreich und bekannt zu sein, meistens war man leider dann schon tot. Ein Dichter zu werden aber, das war unmöglich, es werden zu wollen, war eine Lächerlichkeit und Schande, wie ich sehr bald erfuhr. Es war mit dem Dichter genauso, 
wie es mit den Helden war ... alle Schulbücher standen voll ihres Lobes, in der Gegenwart und Wirklichkeit aber hasste man sie ...74

Mit dem Abbruch der Schulausbildung und der Rückkehr nach Calw begann der 16-jährige Hesse einen bewußt professionellen, autodidaktischen Literaturunterricht. Außerdem half er dem Vater im Calwer Verlagsverein und beschäftgte sich mit Gartenarbeit. Es folgten einige Versuche als Lehrling, zuerst in einer Buchhandlung in Esslingen, wo er schon nach vier Tagen weglief, dann in der Turmuhrenfabrik in Calw, wo er ab Juni 1894 als Praktikant in der mechanischen Werkstatt arbeitete. In jenem Jahr, er blieb bis September 1895, in dem er täglich an der Drehbank stand, feilte, bohrte, fräste und mit dem Lötkolben hantierte, gelang es Hesse aus eigener Anstrengung seine Krise zu überwinden. 75

Endlich fand er im Oktober 1895 eine angemessenere Lehrstelle in der Buchhandlung J.J. Heckenhauer in Tübingen, wo er vier Jahre blieb (1895-99). Der Sturm hatte nachgelassen. Er schrieb in einem Brief 1885:

Jetzt erst habe ich allmählich wieder Ruhe gefunden, bin geistig gesund geworden ... die böse Zeit voll Zorn und $\mathrm{Haß}$ und Selbstmordgedanken liegt hinter mir, immerhin hat sie mein dichterisches Ich ausgebildet; die tollste Sturm- und Drangzeit ist glücklich überstanden. 76

Welch große Bedeutung diese Jugendphase für Hermann Hesse hatte, zeigte sich später immer wieder in seinen Dichtungen, besonders in der Behandlung der Themen Kindheit und Jugend, Schule und Erwachsenwerden. Dem Themenkreis der Selbstverwirklichung, Identitätsfindung, der Selbsterziehung, sowie dem Nachdenken und der Realisation von Ausbrüchen

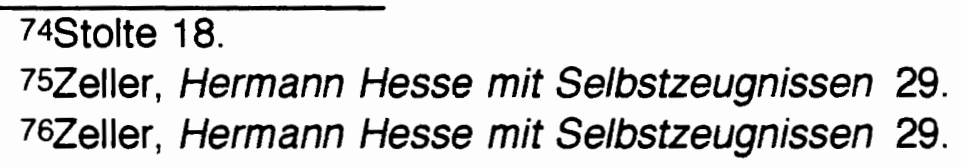


aus den gesellschaftlichen Zwängen widmete Hesse in seinen Werken einen weiten Raum.

Als Lehrling und späterer Sortimentsgehilfe in Tübingen setzte er nach Ladenschluß der Buchhandlung Heckenhauer seine in Calw begonnenen autodidaktischen Studien fort. Sein Interesse galt vor allem der Geistes- und Literaturgeschichte mit dem Schwerpunkt auf Goethe und dem Jahrhundert nach 1790, einschließlich Nietzsche.

Hier in Tübingen begann er, seine literarischen Interessen ohne Zwang des Elternhauses oder der Schule zu verfolgen. Zum Schreiben blieben inm allerdings oft nur die Sonntage, denn er arbeitete zwölf Stunden am Tag, sechs Tage pro Woche. Ende 1895 schrieb er Meine Kindheit, etwas später einen Teil von Hinterlassene Schriften und Gedichte von Hermann Lauscher (1901). Aus Mangel an Freizeit hatte der introvertierte Einzelgänger nicht viele Freunde, schloß sich letztlich aber dem sogenannten 'petit cénacle', einem kleinen Studentenkreis an.

1899 zog Hesse nach Basel, wo er fünf Jahre lang wohnte, ebenfalls in einer Buchhandlung arbeitete und seine erste Frau Maria Bernoulli kennenlernte, die er im Jahre 1094 heiratete. Inzwischen arbeitete er an sich selbst, indem er eine Selbstanalyse mit dem Arzt Josef Lang begann, die er einige Jahre später mit C. G. Jung fortsetzte. Bald wurde Hesse Mitarbeiter bei Zeitschriften, sowie Mitherausgeber der Zeitschrift März, einer liberalen Wochenschrift, die sich direkt gegen die persönliche Autorität von Kaiser Wilhelm II richtete und im Januar 1907 zum ersten Mal erschien.

Hesse sollte in seinem Leben noch viele Höhen und Tiefen durchleben. 1923 ließ er sich von Maria, der Mutter seiner drei Söhne Bruno, Heiner und 
Martin, scheiden und heiratete schon im folgenden Jahr Ruth Wenger. Diese Ehe überlebte nur drei Jahre und endete ebenfalls in Scheidung. Von 1919 an lebte Hesse hauptsächlich in Montagnola, unternahm lange Reisen und bevorzugte nach wie vor ein eher zurückgezogenes Leben. So verlebte er die späteren Jahre seines Lebens mit seiner dritten Frau Ninon Dolbin, geb. Ausländer, bescheiden und zurückgezogen.

1946 erhielt Hermann Hesse für Das Glasperlenspiel (1943) den Nobelpreis für Literatur und den Goethe-Preis.

Hesse starb am 9. August 1962 in Montagnola im Alter von 85 Jahren.

\section{Autobiographische Elemente in den literarischen Figuren}

Die Erzählung Unterm Rad repräsentiert nicht nur die frühe Schaffensphase des Schriftstellers, sondern auch eine frühe Phase seines langen Lebens. Hesse wollte Erlebnisse und Krisen der eigenen Entwicklungsjahre mit diesem Werk verarbeiten und sich von der Erinnerung an sie befreien. Von allen größeren Erzählungen und Romanen Hesses ist Unterm Rad das wohl am meisten autobiographisch gefärbte Werk.

Obwohl anzunehmen ist, daß Hesse bei der Zentralfigur, dem Anti-Helden Hans Giebenrath, mehr an seinen jüngeren Bruder Hans dachte, der lange nach Erscheinen von Unterm Rad Selbstmord beging, sind doch viele Parallelen zwischen Hans Giebenrath und Hermann Hesse zu entdecken. Immerhin wächst Hans Giebenrath in Calw auf, geht dort zur Schule und verfolgt den gleichen Bildungsweg wie einst Hesse selbst, bis zum Besuch und schließlichem Austreten aus dem Maulbronner Seminar. Der stark autobiographische Charakter der Erzählung wird an vielen Details besonders deutlich. So hatte auch Hesse als Junge einen "Lattenverschlag in meines 
Vaters Garten, da hatte ich Kaninchen und einen gezähmten Raben leben. Dort hauste ich unendliche Stunden, lang wie ein Weltzeitalter, in Wärme und Besitzerwonne". 77

Hesse hat bei der Beschreibung der körperlichen Eigenschaften des Hans Giebenrath den er als eher schwächlichen, zu Kopfschmerzen neigenden Jüngling darstellt, sicher an seine eigene Statur als Knabe gedacht. Wenn auch körperlich wenig belastbare Burschen, so konnten doch sowohl Hesse als auch Giebenrath stundenlanges Umherstreifen in der Natur genießen. Immer wieder stößt man als Leser von Hesses Biographien auf erstaunliche Einzelheiten, die der Schriftsteller in diesem Werk verarbeitet hat. Wie Giebenrath seine Lehrer und Tutoren in der Zeit der Vorbereitung auf das Landexamen ihres unendlich erscheinenden Wissens wegen bewundert, ist auch für Hesse die kurze Periode der Göppinger Schulzeit, der einzigen, in der er ein wirklich guter Schüler war und seine Lehrer verehrte, eine erfolgreiche Zeit.

Sobald der Leser in Unterm Rad jedoch mit Hermann Heilner, den Mit- und Gegenspieler von Hans Giebenrath, bekannt gemacht wird, ist zu erkennen, daß Hesse seine eigene Persönlichkeit noch mehr in dieser Figur darstellt. Heilner ist von Anfang an als Suchender, Fragender und Zweifelnder charakterisiert. Er denkt, wie auch Hesse, schon in sehr frühen Jugendjahren über den Sinn seiner Existenz nach und akzeptiert nicht ungefragt, was inm von den Erwachsenen vorgelebt wird. Heilner „war an Leib und Seele über sein Alter entwickelt und begann schon versuchsweise eigene Bahnen zu wandeln."78

Heilner wird nicht wie Giebenrath als braver Musterknabe beschrieben,

77 GW VI, 374.

78UR 61. 
sondern ist als leichtsinnig, aggressiv und lyrisch talentiert dargestellt. Hesse selbst beschreibt sich in diesem Alter als einen schwierigen und sehr unartigen Sohn, mit dem die Eltern nicht mehr fertig wurden. 79

Mit Heilners Flucht aus der Klosterschule beschreibt Hesse wiederum ein Erlebnis, das er selbst durchgemacht hatte. Er selbst war schon im ersten Jahr "ohne sichtlichen Anlaß oder zureichenden Grund, ohne Geld, ohne Mantel nach dem Mittagessen" weggelaufen 80 Auch Heilner bleibt in Unterm Rad eine Nacht dem Kloster fern, wird am nächsten Tag von einem Landjäger aufgegriffen und ins Kloster zurückgebracht. Nachdem Heilner von der Schule gewiesen wird, erfahren wir von inm nur noch, daß später doch noch ein Mann aus inm geworden ist. Ob er es geschafft hat, Dichter zu werden, bleibt dem Leser vorenthalten.

In Hermann Hesses jungem Leben beginnt nach der Flucht aus dem Kloster die eigentliche Jugendkrise. Hesses Schwächezustände und häufige Kopfschmerzen, später Selbstmordgedanken findet man in der Erzählung bei Giebenrath wieder. Während Giebenraths Leben jedoch von Kräften anderer gelenkt wird, ist bei dem jugendlichen Hesse ein verzweifelter Kampf um Selbstbehauptung zu erkennen. Die Verteidigung der eigenen Wünsche, des eigenen Ichs und der früh bewußt gewordenen Begabung zum Dichten ist das Ziel von Hesses rebellischem Aufbegehren. Die zahlreichen schulischen Mißerfolge, die Enttäuschung erster Liebe, das Gefühl, von den Eltern nicht mehr geliebt zu werden und das innere Hadern mit Gott und der Welt führen bei Hesse zu Selbstmordgedanken und zwei tatsächlichen Versuchen.

Erst als Hesse von seinen Eltern die Erlaubnis bekommt, seine formelle

79Zeller, Hermann Hesse mit Selbstzeugnissen 20.

80Zeller, Hermann Hesse mit Selbstzeugnissen 27. 
schulische Ausbildung endgültig abzubrechen, beginnt er sich langsam wieder auf sie zu besinnen und seine Jugendkrisen schließlich zu überwinden. Aus eigenem Willen entschließt er sich, als Praktikant in die mechanische Werkstatt der Calwer Turmuhrenfabrik einzutreten, während Giebenrath von seinem Vater vor die Wahl gestellt wird, Schreiber oder Mechaniker zu werden, gleich noch mit einem Ultimatum für die Entscheidung. „Überleg dir's ordentlich. Wir reden dann morgen darüber." 81

Mit Beginn der Lehre als Buchhändler in Tübingen war Hesse fest entschlossen, Dichter zu werden. Seine autodidaktischen Studien, die er in Calw begonnen hatte, setzte er dort fort. Er war auf der Suche nach der eigenen Identität zwar noch nicht am Ziel angekommen, doch er war auf dem besten Wege dahin. Sein Leben hatte wieder einen Sinn bekommen. An seine Eltern schreibt er: „Die Tagesarbeit ermüdet wohl, weckt aber auch das Verlangen, den Staub abzuwaschen und verdoppelt den Reiz geistigen Genusses ... Eigentlich ist es doch die private Arbeit, die mir das Leben wert macht, mein bischen Studieren."82 Im Gegensatz zu Giebenrath resigniert Hesse nicht, wenn auch der Weg zum eigenen Ich, zur Identität als Dichter, nicht immer leicht für inn ist.

Die Spaltung in zwei Charaktere in Unterm Rad reflektiert die Diskrepanz zwischen dem idealen Dichterleben, das Hesse führen wollte und der Wirklichkeit mit Flucht und Krisen. Der verlorene Junge, der sich selbst zu finden versucht, von seinen Lehrern jedoch mißverstanden wird, und von Krankheit und Selbstmordgedanken geplagt ist, wird in der Figur des Hans Giebenrath portraitiert. Mit der Figur des Hermann Heilner zeigt Hesse sein

81 UR 136.

82Zeller, Hermann Hesse mit Selbstzeugnissen 33. 
Verlangen nach wirklicher Freiheit von Autoritätspersonen wie Eltern und Lehrern. Heilner verkörpert ein idealisiertes Bild, wie Hesse sich selbst gern gesehen hätte. Heilner hatte den Mut, seinem Haß und seiner Abscheu gegen Mitschüler und Lehrer freien Lauf zu lassen, was der junge Hesse nicht wagte. Heilner begleitet Giebenrath. Der Eine will sich selbst zufriedenstellen, der Andere anderen gefällig sein. Der jugendliche Hesse ist in beiden Figuren wiederzuerkennen. 


\section{KAPITEL V}

\section{ZUSAMMENFASSUNG}

Seit der industriellen Revolution, nur knapp ein Jahrhundert vor der Geburt von Hermann Hesse, ist es jungen Menschen in größerem Umfang möglich geworden einen Beruf zu ergreifen, der nicht der des Vaters, bzw. der Eltern war. Zuvor gab ein Bauer, Müller oder Schuhmacher die Kenntnisse und Fähigkeiten, die er selbst von seinen Eltern erlernt hatte, an seine Kinder weiter, indem er sie an seinem Beruf tagtäglich teilhaben ließ. Diese Kinder, die von klein auf den Eltern bei der Arbeit in Haus und Hof oder Werkstatt helfen mußten, hatten, so ist anzunehmen, weniger Schwierigkeiten beim Finden der eigenen Identität, denn der Berufsweg war vorgegeben. Es war in vielen Fällen selbstverständlich und bedurfte weniger Suche nach der geeigneten Berufung, wenn es darum ging, was aus einem jungen Menschen werden sollte. Erst mit zunehmender Industrialisierung der westlichen Länder kam es zu einer Notwendigkeit für allgemeine schulische und berufliche Ausbildung.

Je mehr technischen Fortschritt wir erleben, desto mehr Zeit ist notwendig für eine endgültige Ich-Findung, die nicht zuletzt mit dem Erlangen einer hochspezialisierten Berufsausbildung im Leben eines jungen Menschen zusammenhängt. Die Zeit der Jugend wird zu einem besonders bewußten und wichtigen Lebensabschnitt, in dem man lernt, sich selbst mit seinen Fähigkeiten und Grenzen zu akzeptieren. Das Finden der eigenen Identität ist weder für den durchschnittlich intelligenten noch für den begabten und kreativen Jugendlichen eine einfach zu bewältigende Aufgabe. Bedrängt vom 
physiologischen Veränderung ihrer geschlechtlichen Reifung und der Ungewißheit, was von innen als zukünftige Erwachsene erwartet wird, flüchten sich Jugendliche manchmal in eine scheinbar merkwürdige Befangenheit über ihre äußere Erscheinung in den Augen von anderen. Auf der Suche nach einem neuen Gefühl der Kontinuität und Gleichheit müssen manche Jugendliche sich mit Krisen früherer Jahre auseinandersetzen, bevor sie anhaltende Idole und Ideale als Wächter für ihre endgültige Identität einsetzen können. 83

Der Leser begegnet in Unterm Rad in der Figur des Hermann Heilner einem Jugendlichen, der zwar noch mit der Suche nach dem Sinn des Lebens ringt, sich aber schon seiner Außenseiterrolle bewußt wird und zu inr steht. Er ist anderen gegenüber nicht befangen, im Gegenteil, es kümmert inn wenig, was Lehrer und Mitschüler von inm halten. Auch gibt er bei der Verfolgung seiner Ideale äußeren Einflüssen nicht nach, ist sogar zu absoluter Konsequenz bereit, bis zum Ausschluß aus der Klosterschule.

Hans Giebenrath hingegen lebt scheinbar nur, um anderen gefällig zu sein, sogar noch dann, als inn sein Freund Heilner durch Verspottung seiner Streberei zum selbständigen Denken anregt. Hans bemerkt gar nicht, daß er sozusagen mit einer geborgten Identität lebt, nämlich der des Primus, zu dem inn hauptsächlich die Erwachsenen machen wollen. Nachdem Hans die Klosterschule verläßt, versucht er, in seine verlorene Kindheit zu flüchten und sie nachzuholen. Doch auch in der ärmlichen Gasse seiner Kindheitsspiele findet er niemanden, der inn aus der Verzweiflung retten kann.

Im Roman Demian führt Emil Sinclairs Weg der Selbstfindung durch die dichotomische lch- und Welterfahrung zur Entgrenzung des in der frühen 
Kindheit als Einheit erlebten Ichs.84 Als Zehnjähriger nimmt Emil die behütete Alltagswelt des Elternhauses mit ihrer Rechtschaffenheit, ihrer inneren und äußeren Ordnung und ihrer warmen Behaglichkeit wahr. Gleichzeitig lernt er die dunkle Welt lockender Abenteuer, unbekannter Gefahren der Erpressung kennen. „Und das Seltsamste war, wie die beiden Welten aneinander grenzten, wie nah sie beisammen waren." 85 In diesem Roman wird deutlich, daß der Jugendliche Emil zuerst seine Krisen aus der Kindheit verarbeiten muß, was schließlich mit Hilfe seines Freundes Max Demian gelingt, bevor er zur IchFindung als erwachsener Mann gelangen kann.

Hermann Hesse weiß, wie die von inm geschaffene Figur des Hermann Heilner, daß er Dichter werden will, sieht aber im Alter von dreizehn bis sechzehn Jahren keinen ihm möglichen Weg, zu diesem Ziel zu gelangen. Sich von den Erwachsenen mißverstanden fühlend und den Altersgenossen intellektuell überlegen befindet sich auch Hesse als Jugendlicher in der Rolle des Außenseiters. Dies ist eine besonders schwierige Rolle, denn die meisten jungen Leute wollen auf keinen Fall anders sein, auffallen oder abgesondert werden, vielmehr wollen sie "mit der Masse schwimmen”.

Hesse gibt viele Jahre später in Briefen an junge Menschen immer wieder mehr oder weniger ermutigende Empfehlungen, die jedoch oft wenig präzise sind. An einen „jungen Problematiker" schreibt er zum Beispiel:

Ja, sagen Sie ja zu sich, zu ihrer Absonderung, Ihren Gefühlen, Ihrem Schicksal! Es gibt keinen anderen Weg. Wohin er führt, weiß ich nicht, aber er führt ins Leben, in die Wirklichkeit... Sie können inn

84Bernhard Sowinski und Reinhard Meurer (Hrsg.), Oldenbourg Interpretationen mit Unterrichtshilfen. Hermann Hesse. Demian. Unterm Rad (München: Oldenbourg Verlag $\mathrm{GmbH}, 1989) 18$.

85 Unseld 54. 
unerträglich finden und sich das Leben nehmen, das steht jedem offen, der Gedanke daran tut oft wohl, auch mir. 86

Wie dieses Leben, diese Wirklichkeit aussieht, muß der Empfänger von Hesses Brief selbst entscheiden, denn konkrete Ratschläge bekommt er nicht. Aber die Entscheidung, wie die Wirklichkeit des eigenen Lebens aussehen soll, muß schließlich jeder Mensch selbst treffen: ob er sich als Außenseiter fühlt oder den Anschluß an die "Normalen" bevorzugt.

Hesse versucht, seine Leser zum Nachdenken über das eigene Leben, das eigene Ich anzuregen. Fast alle seiner Helden sind Bedrohte, Flüchtende, Wandernde, Selbstmörder und Heimatlose. Diese Personen machen ungeheure Metamorphosen, Wandlungen und Veränderungen durch. Sie kämpfen um ihre Individuation. Der Leser nimmt an ihren Wandlungen und Kämpfen teil, und es kommt vor, daß er sich selbst in innen erkennt. 87 Wie Hesse selbst ein Leben lang der Fragende und Suchende war, ermutigt er auch seine jugendlichen Leser, selbstkritisch zu ergründen und zu prüfen, wer sie sind und wer sie in der Zukunft möglicherweise sein könnten.

Hermann Hesse hat als junger Mann Vorbilder wie Goethe und Nietzsche, mit denen er sich hauptsächlich während seiner Ausbildung zum Buchhändler beschäftigt. Dieser Einfluß wird schon in seinem ersten Roman Peter Camenzind sichtbar. Obwohl er sich als das ideale Leben das eines Dichters vorstellen kann, ist seine eigene Ich-Findung zu Beginn des Erwachsenseins noch nicht beendet. Als über Dreißigjähriger und Familienvater von drei Söhnen wird inm die bürgerliche Seßhaftigkeit zur Qual und es zieht inn immer häufiger auf Reisen. Er schreibt über diese Zeit: "Ich hatte mir als junger

86Volker Michels (Hrsg.), Hermann Hesse. Lektüre für Minuten Bd. 1, 15. Auflage (Frankfurt: Suhrkamp Verlag, 1980) 61.

87Karin Struck in Michels, Über Hermann Hesse 324. 
Mensch das Mannesalter ganz anders vorgestellt. Nun ist es auch wieder ein Warten, Fragen und Unruhigsein, mehr Sehnsucht als Erfüllung."88 Sogar noch im Alter von über sechzig Jahren beschäftigt sich Hesse mit der Identität, dem Ich. In einem Brief vom Mai 1943 schreibt er:

In jedem von uns sind zwei lch, und wer immer wüßte, wo das eine beginnt und das andere aufhört, wäre restlos weise.

Unser subjektives, empirisches, individuelles Ich, wenn wir es ein wenig beobachten, zeigt sich als sehr wechselnd, launisch, sehr abhängig von außen, Einflüssen sehr ausgesetzt...

Dann ist aber das andere Ich da, im ersten verborgen, mit inm vermischt, keineswegs aber mit ihm zu verwechseln. Dies zweite, hohe, heilige Ich ... ist nicht persönlich, sondern ist unser Anteil an Gott, am Leben, am Ganzen, am Un- und Überpersönlichen. Diesem Ich nachzugehen und zu verfolgen lohnt sich schon eher. Nur ist es schwer, dies ewige Ich ist still und geduldig, während das andere Ich so vorlaut und ungeduldig ist. 89

Wie es Hesse für sich selbst als Lebensnotwendigkeit erkannt hat immer den Fragen nach der eigenen Identität, nicht zuletzt der eigenen Aufgabe der Menschheit als Gesamtes gegenüber, nachzugehen und Antworten zu finden, so stehen alle Menschen vor dieser Aufgabe. Mit dem Suchen aufzuhören oder es von Anfang an als unwichtig zu erachten, würde bedeuten, das wirkliche Leben zu beenden und nur noch vor sich hin zu vegetieren.

Die Tatsache, daß Hans Giebenrath nur kümmerlich dahinlebt, ohne einen Sinn für seine Bemühungen zu erkennen und selten wahre Lebensfreude zu

\footnotetext{
88Zeller, Hermann Hesse mit Selbstzeugnissen 64.

89R. H. Farquharson, "The Identity and Significance of Leo in Hesse's 'Morgenlandfahrt'". Monatshefte 55, 3 (1963) 122-27.
} 
verspüren, macht Hesse den Eltern und Lehrern in seiner Erzählung zum Vorwurf. Der Vater von Hans, der nur dessen Studieren, nicht aber das KindSein unterstützt, erhofft sich sozialen Aufstieg durch den Sohn. Die Lehrer hoffen, sich selbst Ruhm zu verschaffen, indem sie einen Primus heranziehen. Auf die Bedürnnisse des Knaben achtet keiner der Erwachsenen.

Im Roman Roßhalde ist die Beziehung zwischen dem Maler Johann Veraguth und seinem kleinen Sohn Pierre ebenso eindrucksvoll beschrieben. Denn auch dieses Kind stirbt letztendlich an der Nachlässigkeit eines Vaters, der zu wenig Zeit und Aufmerksamkeit für sein Kind hat, als es noch gesund ist. Der in seine Arbeit versunkene Künstler stößt das Kind oft zurück, das die Nähe und Aufmerksamkeit des Vaters sucht.

Hesse übt jedoch nicht nur Kritik an seinen ehemaligen Lehrern, sondern am ganzen damaligen Erziehungssystem, das versäumte das Kind als Individuum $z u$ verstehen und in diesem Sinne zu erziehen. Vor allem in den höheren Schulen bestand das Hauptziel in der sogenannten „klassischen Bildung”. Für Kreativität, individuelie Talente oder handwerkliche Ausbildung gab es in den Lehrplänen der damaligen Gymnasien keinen Raum. "Die Dressurmaßnahmen, die diesem Muster [dem der humanistischen Gymnasien] folgen, lassen sich als 'Erziehung' kaum noch interpretieren. Ihr Ziel ist nicht die Ich-Entwicklung des Kindes, sondern die Wiederaufrichtung der gestörten Identität des 'Erziehers'..."90

Der Volkserzieher Johann Heinrich Pestalozzi erkannte schon zu Anfang des 19. Jahrhunderts, daß die Erziehung auf Anschauung als den inneren Sinn des Menschen für die Ordnung der Welt, auf Liebe und Glauben zu gründen ist. Er betonte die 'bildende' Kraft der Arbeit und des Gemeinschaftslebens; vor

90Annette Leppert-Fögen, Die deklassierte Klasse (Frankfurt a. M.: Fischer Verlag, 1974) 231. 
allem sah er als Vorbild aller Erziehung die Familie. „Alles, was der Mensch ist, will und soll, geht von inm aus, dem Mittelpunkt unseres ganzen Seins...". 91 Was man als Mensch ist, will und soll, kann meines Erachtens nach jedem Kind am besten von den Eltern, bzw. einer stabilen Familie mit auf den Lebensweg gegeben werden.

In diesem Sinne zeigt Hesse dem Leser, daß für Hans Giebenrath eine Rettung durch erfolgreiche Identitätsfindung nicht möglich ist. Was Hans will und soll geht nicht von ihm selbst aus. Die durch den Leistungsdruck unbewußt verdrängten Triebe kann er weder durch geistige, noch durch handwerkliche Leistungen ersetzen. Der Tod ist für inn eine Erlösung.

Jeder Mensch ist ein einmaliges Individuum, das als Kind unter Anleitung von Eltern und Lehrern, und später selbständig daran arbeiten muß, die eigene Identität, den Sinn dieses einmaligen Lebens zu finden. Ein jeder von uns ist zu ganz bestimmten Aufgaben berufen, die es zu erkennen, erforschen und im jeweils möglichen Maße zu bewältigen gilt. Deswegen ist die individuelle Vielfalt unter den Menschen so wertvoll. In seinem Roman Demian drückt Hesse seine Dankbarkeit für diese Vielfalt der Natur meines Erachtens ganz hervorragend aus:

Jeder Mensch aber ist nur er selber, er ist auch der einmalige, ganz besondere, in jedem Fall wichtige und merkwürdige Punkt, wo die Erscheinungen der Welt sich kreuzen, nur einmal und so nie wieder. Darum ist jedes Menschen Geschichte wichtig, ewig, göttlich, darum ist jeder Mensch, solange er irgend lebt und den Willen der Natur erfüllt, wunderbar und jeder Aufmerksamkeit würdig. In jedem ist der Geist Gestalt geworden, in jedem leidet die Kreatur, in jedem wird ein Erlöser 91Ernst Otto, Pestalozzi. Werk und Wollen (Berlin: Walter de Gruyter \& Co. Verlag, 1948) 34. 
gekreuzigt. 92

Diese Einzigartigkeit ist etwas Wunderbares, wofür wir unserem Schöpfer dankbar sein dürfen. Es ist somit unsere Aufgabe, sie zu erhalten und zu fördern.

Als Eltern, Erzieher und Lehrer sollten wir deswegen auch heute und morgen nie vergessen, daß jedes unserer Kinder und jeder unserer Schüler, unserer ungeteilten Aufmerksamkeit würdig ist. Es gilt nach wie vor, Individuen $z u$ erziehen und jungen Menschen dabei zu helfen, den Ausgangspunkt zu finden, von dem aus sie ihr eigenes Leben zu gestalten fähig sind. Alle anderen Absichten in der Erziehung behindern die individuelle Entwicklung, anstatt sie zu fördern. Auf der Suche nach der eigenen Identität am Ziel angekommen, sollte jeder Mensch imstande sein, seinen eigenen Beitrag bei der Lösung von gesellschaftlichen Aufgaben im Bereich von Politik Wirtschaft, Erziehung und Kultur zu leisten. 


\section{EINE AUSWAHLBIBLIOGRAPHIE}

Häufig zitierte Werke sind im Text durch folgende Abkürzungen kenntlich gemacht:

GS: Hesse, Hermann. Gesammelte Schriften. Bände I -VII. Frankfurt am Main: Surhkamp Verlag, 1978.

GW: Hesse, Hermann. Gesammelte Werke in zwölf Bänden. Frankfurt am Main: Suhrkamp Verlag, 1987.

UR: Hesse, Hermann. Unterm Rad. 13. Auflage. Frankfurt am Main: Surhrkamp Verlag, 1979.

Ball, Hugo. Hermann Hesse: Sein Leben und Werk. Frankfurt am Main: Suhrkamp Verlag, 1967.

Böttger, Fritz. Hermann Hesse: Leben, Werk, Zeit. Berlin: Verlag der Nation, 1974.

Boulby, Mark. Hermann Hesse:His Mind and Art. Ithaca: Cornell University Press, 1967.

Brockhaus (Hrsg.). Der Neue Brockhaus. Wiesbaden: F.A. Brockhaus, 1973.

Christensen, Jens. Der moderne Bildungsschwindel in Schule und Familie sowie im täglichen Verkehr. Leipzig: ohne Verlagsangabe, 1885.

Erikson, Erik T. Identity: Youth and Crisis. New York: Norton Press, 1968.

Farquharson, R.H. "The Identity and Significance of Leo in Hesse's 'Morgenlandfahrt". Monatshefte 55 (1963): 122-27.

Feinleib, Maria R. "Youth Suicide," Report of the Secretary's Task Force. Washington:US Government Print Office, 1989.

Field, George Wallis. Hermann Hesse. New York: Twayne Publishers, Inc., 1970.

Freedman, Ralph. Hermann Hesse. Pilgrim of Crisis. A Biography. New York: Pantheon Books, 1978. 
Freeman, Joan (Hrsg.). Psychology of Gifted Children: Perspectives on Development and Education. Bury St. Edmunds: St. Edmundsbury Press, 1985.

Groth, Max. „Unterm Rad. Von Hermann Hesse.” Der Kunstwart 19, 5 (1905): 283-84.

Günther, Karl-Heinz u.a. Geschichte der Erziehung. Berlin: Volk und Wissen Volkseigener Verlag, 1957.

Haas, Gerhard. Literatur im Unterricht. Modelle zu erzählerischen und dramatischen Texten in der Sekundarstufe I und II. Stuttgart: Reclam Verlag, 1982.

Hesse, Ninon (Hrsg.). Kindheit und Jugend vor Neunzehnhundert: Hermann Hesse in Briefen und Lebenszeugnissen 1877 - 1895. Frankfurt am Main: Suhrkamp Verlag, 1966.

Koester, Rudolf. "Self-Realization: Hesse's Reflection on Youth." Monatshefte 57 (1965): 181-86.

Leppert-Fögen, Annette. Die deklassierte Klasse. Frankfurt am Main: Fischer Verlag, 1974.

Michels, Volker. Hermann Hesse: Leben und Werk im Bild. Frankfurt am Main: Insel Verlag, 1973.

Verlag, 1977.

Über Hermann Hesse. Bd. 2, Frankfurt am Main: Suhrkamp

(Hrsg.). Hermann Hesse. Lektüre für Minuten. Bd. 1, 15. Auflage. Frankfurt am Main: Suhrkamp Verlag, 1980.

Mileck, Joseph. Hermann Hesse. Biography and Bibliography. Bd. 1. Los Angeles: University of California Press, 1977.

Otto, Ernst. Pestalozzi. Werk und Wollen. Berlin: Walter de Gruyter \& Co., 1948.

Pfeifer, Martin. Hesse-Kommentar zu Sämtlichen Werken. München: Winkler Verlag, 1980.

Reichert, Herbert. The Impact of Nietzsche on Hermann Hesse. Mt. Pleasant: The Enigma Press, 1972.

Rose, Ernst. Faith from the Abyss: Hermann Hesse's Way from Romanticism to Modernity. New York: New York University Press, 1965. 
Schneider, Christian Immo. Hermann Hesse. München: C.H. Beck Verlag, 1991.

Schweikle, Günther und Irmgard (Hrsg.). Metzler Literaturlexikon. Begriffe und Definitionen. Stuttgart: J.B. Metzlersche Verlagsbuchhandlung, 1990.

Sowinski, Bernhard und Meurer, Reinhard. Oldenburg Interpretationen mit Unterrichtshilfen. Hermann Hesse. Demian. Unterm Rad. München: Oldenbourg Verlag, 1989.

Stolte, Heinz. Weltscheu und Lebensliebe. Hamburg: Hansa Verlag, 1971.

Unseld, Siegfried. Hermann Hesse: Werk und Wirkungsgeschichte. Frankfurt am Main: Surhkamp Verlag, 1985.

Zeller, Bernhard. Hermann Hesse in Selbstzeugnissen und Bilddokumenten. 29. Auflage. Reinbek bei Hamburg: Rowohlt Taschenbuch Verlag, 1993.

Zeller, Bernhard (Hrsg.). Hermann Hesse: 1877 - 1977. Stationen seines Lebens, des Werkes und seiner Wirkung. München: Kösel Verlag, 1977.

Ziolkowski, Theodore (Hrsg.). Autobiographical Writings. New York: First Noonday Printing, 1973.

Prentice Hall, 1973.

Hesse: A Collection of Critical Essays. New Jersey: 